\title{
Cytokinesis in Metazoa and Fungi
}

\section{Michael Glotzer}

Department of Molecular Genetics and Cell Biology, University of Chicago, Chicago, Illinois 60637

Correspondence:mglotzer@uchicago.edu

\section{SUMMARY}

Cell division—cytokinesis—involves large-scale rearrangements of the entire cell. Primarily driven by cytoskeletal proteins, cytokinesis also depends on topological rearrangements of the plasma membrane, which are coordinated with nuclear division in both space and time. Despite the fundamental nature of the process, different types of eukaryotic cells show variations in both the structural mechanisms of cytokinesis and the regulatory controls. In animal cells and fungi, a contractile actomyosin-based structure plays a central, albeit flexible, role. Here, the underlying molecular mechanisms are summarized and integrated and common themes are highlighted.

\section{Outline}

1 Introduction

2 Cellular structures that orchestrate cytokinesis

3 Spatiotemporal control-Introduction

4 Contractile ring assembly and constriction

5 Reconstitution of the contractile apparatus
6 Abscission

7 Context dependence of cytokinetic mechanisms

8 Conclusion

References 


\section{INTRODUCTION}

Cell multiplication requires replication and segregation of the genome and partitioning of the cell contents into two daughter cells through cytokinesis. For this to result in viable, genetically identical daughter cells, the plane of cell division needs to be coordinated with the position of the mitotic spindle. This can be accomplished by the mitotic spindle directing the position of the division plane or by positioning the mitotic spindle with respect to a previously established division plane. Once positioned, the biochemical or structural mark that defines the division plane must give rise to a physical barrier that subdivides the mother cell. The barrier can be created by vesicle fusion and/or constriction of a contractile apparatus that draws in the plasma membrane. Finally, the membrane that serves as the barrier between the cells needs to be fully separateda distinct process termed abscission.

Although the above account constitutes a minimal description of cell division, in some cell types the process is substantially modified. For example, cytokinesis can be coupled with growth to maintain cell size, the division plane can be coordinated with the asymmetric segregation of cortical or cytoplasmic factors, the process of cytokinesis can be completely suppressed as in a syncytial division, or just the final step can be suppressed, generating daughter cells that remain connected but that function autonomously.

Cytokinesis is less well-conserved than nuclear division among eukaryotes. The core molecules that mediate cell cycle progression and nuclear division can be recognized throughout eukaryotes; however, the molecules that facilitate cytokinesis vary among the eukaryote lineages. Members of the opisthokonta clade, including metazoa and fungi (Adl et al. 2012), contain both filamentous (F-) actin and myosin II that assemble into a contractile ring that drives cell division. However, myosin II is absent from many other eukaryotes, including plants, ciliates, and algae (Richards and Cavalier-Smith 2005; Sebé-Pedrós et al. 2014). Cytokinetic mechanisms in opisthokonts, as exemplified by metazoans, and budding and fission yeast are reviewed. As each step in the process of cytokinesis is discussed, the commonalities and differences in cytokinetic mechanisms in animal cells and fungi will be highlighted.

\section{CELLULAR STRUCTURES THAT ORCHESTRATE CYTOKINESIS}

Cytokinesis involves a large-scale reorganization of the contents of the cell. A reorganization of this scale necessitates machinery that can induce cellular-scale rearrangements. The principle driving force for cytokinesis in yeast and metazoa is the actomyosin-based contractile ring. Microtubules play a regulatory role in positioning of the division plane and facilitate the abscission step of cytokinesis.

\subsection{Contractile Ring}

Pioneering analyses in sea urchin embryos showed that the contractile ring contains actin filaments closely apposed to the plasma membrane and aligned circumferentially along the cell equator (Schroeder 1972). In early embryonic divisions, the sea urchin contractile ring is $\sim 8$ - $\mu \mathrm{m}$ wide and projects $\sim 0.2 \mu \mathrm{m}$ into the cytoplasm. In these cells, the ring width and thickness is fairly constant during constriction, implying that significant disassembly of actin filaments occurs while the ring constricts. Individual filaments are relatively short, $\sim 0.25 \mu \mathrm{m}$. Follow-up studies showed the presence of myosin, some assembled into minifilaments, located in the furrow region and associated with actin filaments of mixed polarity (Fujiwara and Pollard 1976; Mabuchi and Okuno 1977; Sanger and Sanger 1980; Yumura et al. 1984; Maupin and Pollard 1986). Many of these essential conclusions have been confirmed by live-cell imaging with fluorescently labeled actin and myosin in diverse animal species and fungi ( $\mathrm{Bi}$ et al. 1998; Bezanilla et al. 2000; Yumura 2001; Murthy and Wadsworth 2005).

\subsection{Accessory Factors of the Contractile Ring}

The components of the contractile ring have been most thoroughly inventoried in the fission yeast Schizosaccharomyces pombe. The major components enriched in the fission yeast contractile ring are actin, myosin II and its essential and regulatory light chains, the anillin-related protein Mid1, the F-BAR protein $\mathrm{Cdc15}$, the formin $\mathrm{Cdc} 12$, the actin-bundling protein $\alpha$-actinin Ain1, the actin-stabilizing protein tropomyosin $\mathrm{Cdc} 8$, and the IQGAP Rng2 (Wu and Pollard 2005). Orthologs of most of these proteins also accumulate in contractile rings in metazoan cells, with the exception of the F-BAR protein Cdc15.

The recruitment mechanisms for many regulatory proteins are reasonably well understood and will be discussed below. In contrast, the mechanisms that control the accumulation of specific actin-binding proteins to the contractile ring as compared with other actin-containing structures in the cell are less well understood. Competition between various actin-binding proteins for binding to particular classes of filaments contributes to this sorting process (Skau and Kovar 2010). For example, fimbrin and tropomyosin mutually antagonize each other's binding to endocytic patches and the contractile ring, respectively. 


\subsection{Accessory Structures in Fission and Budding Yeast}

Ultrastructural analysis of the $S$. pombe contractile ring revealed an arrangement of actin filaments similar to that of animal cells, albeit at a smaller scale (Kamasaki et al. 2007). In the mature ring, the actin filaments average $\sim 600 \mathrm{~nm}$ in length and show interdigitation. Live-imaging studies with fluorescent proteins revealed that the contractile ring assembles from a series of cortical nodes that contain myosin motors and simultaneously nucleate actin assembly (Vavylonis et al. 2008). These nodes assemble into rings by means of a pathway that will be discussed in detail below.

Ultrastructural studies in budding yeast revealed a strikingly ordered set of 10-nm filaments tightly associated with the plasma membrane and restricted to the bud neck (Byers and Goetsch 1976). Subsequent analysis revealed that these filaments are formed by a class of protein called septins (Haarer and Pringle 1987). Multimeric septin complexes constitute the building blocks of these filaments (Sirajuddin et al. 2007). These heteromultimers assemble longitudinally and pair through the carboxy-terminal coiled-coil domains, ultimately forming paired, antiparallel filaments. Despite being highly ordered, the overall arrangements of septin filaments undergo dynamic rearrangement during the cell cycle, being primarily aligned with the axis of the bud neck early in the cell cycle and, later, aligning circumferentially after a single septin ring splits into two rings just before the onset of cytokinesis (Demay et al. 2011). However, septin rings are not contractile; instead, budding yeast assemble an actomyosin contractile ring between the split septin rings.

Yeast cells are surrounded by a rigid cell wall; therefore, cytokinesis must be tightly coupled with remodeling the old cell wall and assembly of a new wall or septum. In budding yeast, the actomyosin-based ring and exocytic deposition of septal material constitute parallel pathways for narrowing the bud neck, either of which can support successful cytokinesis (Vallen et al. 2000).

\subsection{Anaphase Spindle}

In animal cells, the anaphase spindle plays a central role in cytokinetic processes. The anaphase spindle consists primarily of astral arrays of dynamic microtubules and bundled, nonkinetochore, antiparallel spindle microtubules, forming the central spindle. In addition, antiparallel astral rays can sometimes interact, allowing the formation of midzone-like structures in the cell periphery ( $\mathrm{Su}$ et al. 2014).

As will be explained below, the central spindle participates in most steps of cytokinesis. It facilitates division- plane positioning, RhoA activation, assembly of the midbody, and finally abscission, in which the plasma membrane is abscised to generate two separate daughter cells (for a review, see White and Glotzer 2012).

An assortment of microtubule-associated proteins (MAPs) and kinesin motor proteins mediates bundling of the antiparallel, central spindle microtubules (reviewed by Glotzer 2009). Prominent among these microtubule regulators is the centralspindlin complex. Centralspindlin is a heterotetrameric complex consisting of a dimer of the kinesin-6 MKLP1 (or its orthologs [Caenorhabditis elegans ZEN-4, Drosophila melanogaster Pavarotti; MKLP1 hereafter]) stably bound to a dimer of Cyk4/MgcRacGAP (or its orthologs C.e. CYK-4, D.m. RacGAP50C/Tumbleweed; Cyk4 hereafter) (Mishima et al. 2002). Another important protein in the spindle midzone is the MAP Prcl, which preferentially binds to antiparallel microtubules (Jiang et al. 1998; Subramanian et al. 2010). In animal cells, Prc1 complexes with kinesin- 4 and concentrates at microtubule plus ends, where it facilitates bundling of antiparallel microtubules (Subramanian et al. 2013). Prc1 is evolutionarily ancient, being found in diverse eukaryotes, including metazoa, yeast, and plants. In contrast, centralspindlin is restricted to metazoans (Frédéric et al. 2013; M Glotzer, unpubl.).

The chromosome passenger complex is another prominent component of the central spindle. This four-protein complex regulates numerous mitotic events by spatially restricting the localization of its catalytic subunit aurora B (Ruchaud et al. 2007). During mitosis, the complex localizes at kinetochores and, during anaphase, it localizes to both the spindle midzone and the equatorial cortex.

\section{SPATIOTEMPORAL CONTROL- INTRODUCTION}

Cytokinesis is usually coupled to cell cycle progression. However, the degree to which the two processes are coupled varies in different cell types, as do the underlying mechanisms. In metazoan cells, cytokinesis is an anaphase event; cytokinetic events are inhibited until the metaphase-toanaphase transition, whereas, in yeasts, some aspects of division-plane positioning begin soon after the previous division.

Diverse mechanisms contribute to division-plane positioning in different organisms (Oliferenko et al. 2009). However, these processes can be conceptually unified by considering division-plane positioning to be a form of cell polarization wherein a defined domain of the cell acquires special characteristics. Similarly, during cytokinesis, the division plane, frequently the equator, acquires characteristics distinct from the remainder of the cell. This per- 
spective is applicable to essentially all dividing cells, despite the existence of divergent mechanisms. In some cell types, cytokinesis is inextricably coupled to cell polarization. Additionally, the molecular mechanisms that mediate certain types of cell polarization and cytokinesis overlap, both being highly dependent on Rho-family GTPases.

There are a number of pathways by which the cell cortex becomes polarized during cytokinesis. In animal cells, this polarization is manifested by the local activation of the small GTPase RhoA, which is directly involved in assembly of the cleavage furrow. Local RhoA activation creates a membrane-associated domain that favors actin polymerization and myosin activation, ultimately building a contractile ring. In fission yeast, the initial polarization is manifested by the accumulation of a set of relatively stable protein-based nodes in the equatorial cortex ( $\mathrm{Wu}$ et al. 2006). In budding yeast, the division plane is coincident with the site of bud formation, which is triggered by the local activation of the conserved Rho-family GTPase Cdc42. In the following sections, each of these cases will be discussed in detail.

\subsection{Temporal Control in Metazoa}

Most metazoan cells round up during mitosis, thereby altering cell-substrate and cell-cell associations. A number of mechanisms cooperate to induce this cell rounding, including an increase in osmotic pressure that exerts force against a uniformly contractile actomyosin cortex (Stewart et al. 2011) induced by a modest activation of RhoA (Maddox and Burridge 2003; Matthews et al. 2012). During mitosis, the cyclin-dependent kinase Cdk1-cyclin-B phosphorylates centralspindlin, inhibiting its association with the spindle (Mishima et al. 2004), and Ect2, inhibiting its association with both the plasma membrane and centralspindlin (Yüce et al. 2005; Su et al. 2011). Similarly, inhibitory phosphorylation by Cdk1 and the polo-like kinase Plk1 on PRC1 limits PRC1 localization during the cell cycle (Zhu et al. 2006; Hu et al. 2012). PRC1 shows multiple modes of microtubule binding, depending on its interaction partners in the midzone, notably Kif4 (Subramanian et al. 2013).

Cytokinetic events, per se, do not commence until the metaphase-to-anaphase transition, when the anaphasepromoting complex/cyclosome (APC/C) is activated, triggering destruction of cyclin $\mathrm{B}$ and inactivation of Cdk1. Removal of inhibitory mitotic phosphorylations activates cytokinetic regulators, including centralspindlin. Activation of RhoA during anaphase also requires activating phosphorylations, including phosphorylation of the centralspindlin subunit Cyk4 by Plk1. Phospho-Cyk4 binds to the Rho GDP-GTP exchange factor (GEF) Ect2 (Burkard et al. 2009; Wolfe et al. 2009), relieving its autoinhibition.

\subsection{Spindle-Dependent Division-Plane Positioning in Metazoa}

The anaphase spindle is the primary determinant of positioning of the cleavage furrow (Rappaport 1986). It contains bundled antiparallel microtubules forming the spindle midzone and dynamic spindle pole-anchored astral microtubules. These structures appear to function coordinately, the dominant structure depending on the cell type in question (Fig. 1A). Occasionally, spindle-independent mechanisms influence the position of the division plane.

The centralspindlin complex is required for divisionplane specification in metazoan cells. This complex localizes prominently to the spindle midzone, which lies at variable distances from the cell membrane, raising the question of how it impacts events on the membrane when they are well separated. Indeed, a second, smaller pool of centralspindlin that localizes to the plasma membrane has recently been shown to play a role (Basant et al. 2015). The Cyk4 subunit of centralspindlin contains a weak membranebinding domain (Lekomtsev et al. 2012). During anaphase, centralspindlin undergoes regulated oligomerization. Oligomerization promotes the microtubule association of centralspindlin (Hutterer et al. 2009) and membrane localization (Basant et al. 2015) through distinct domains. Centralspindlin activates the RhoGEF Ect2, which activates RhoA at the plasma membrane; thus, these interactions could direct positioning of the division plane (Fig. 1B,C) (Yüce et al. 2005; Burkard et al. 2009; Zhang and Glotzer 2015).

The equatorial localization of centralspindlin is proposed to be under control of the chromosome passenger complex that accumulates at the site of the presumptive furrow (Cooke et al. 1987; Basant et al. 2015). Aurora B kinase-the catalytic subunit of this complex-promotes centralspindlin oligomerization (Douglas et al. 2010). The mechanism of Aurora B localization is incompletely understood, although the kinesins of the Kif20 family (also called MKLP2) and Kif4 are required in vertebrate systems (Gruneberg et al. 2004; Nguyen et al. 2014). Although the membrane-bound pool of centralspindlin is important when the midzone and cortex are far apart, in cells in which they are closer, or once the furrow has begun to ingress, in larger cells, the midzone pool of centralspindlin and associated ECT-2 likely sustain furrow ingression (Yüce et al. 2005; Lekomtsev et al. 2012).

\subsection{Spindle-Independent Positioning of the Division Plane in Metazoa}

Although the centralspindlin complex promotes furrow formation, in a number of cell types furrow formation can occur when this complex is disrupted, aurora B is inhibited, or the spindle midzone is disrupted. For example, 


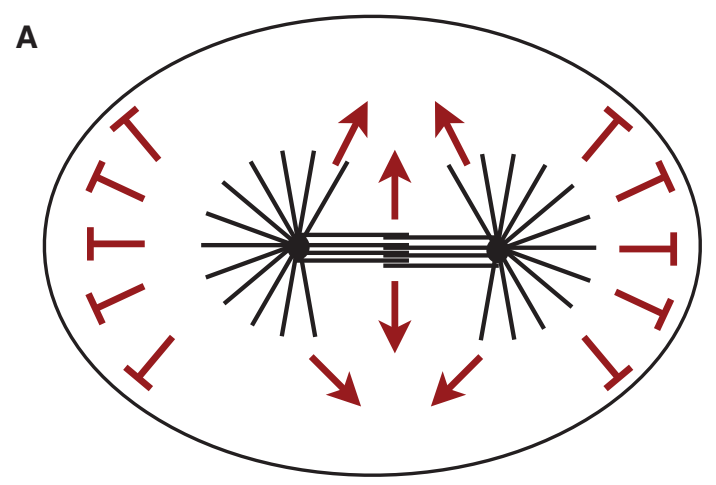

B
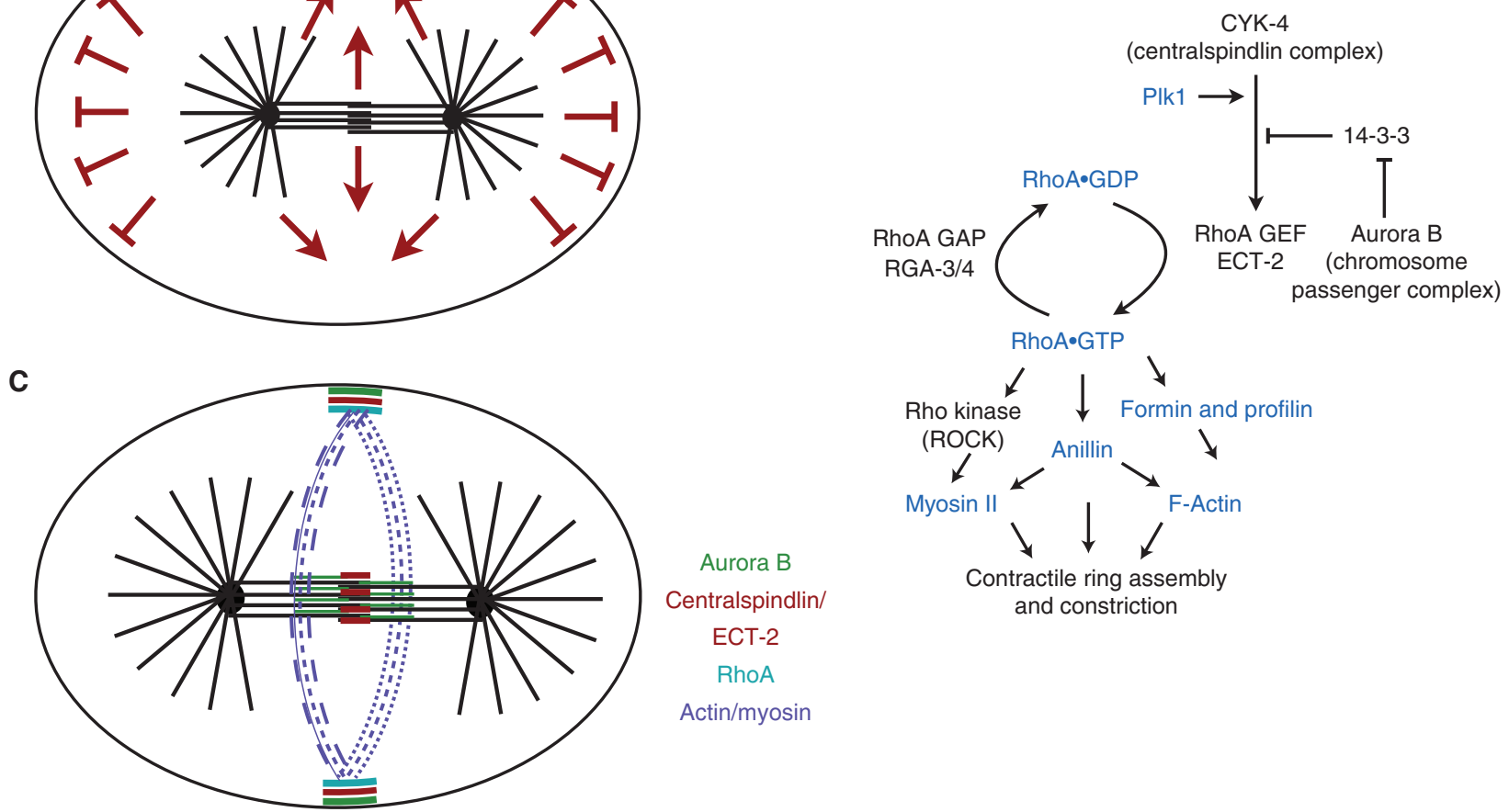

Figure 1. Cytokinesis in metazoa. (A) Overview of the mechanism of division-plane positioning. Furrow position is determined by the position of the mitotic spindle. Positive signals from the spindle midzone and bundled astral microtubules cooperate with inhibitory signals from dynamic astral microtubules to position the division plane. $(B)$ Pathway that induces accumulation of contractile ring components. Components conserved between metazoa and yeast are highlighted in blue. $(C)$ Spatial organization of the activators of contractile ring components and schematic depicting the contractile ring assembled from short actin filaments. GAP, GTPase-activating protein; GEF, GDPGTP exchange factor.

in C. elegans embryos, a second, NOP-1-dependent pathway for RhoA activation can promote furrow formation in centralspindlin-defective embryos (Raich et al. 1998; Tse et al. 2012). NOP-1 primarily promotes contractility and polarization of the fertilized zygote and secondarily induces global activation of RhoA and its effectors during cytokinesis. Cultured mammalian cells depleted of the kinesin6 subunit of centralspindlin can also form furrows (Yüce et al. 2005). In both these cases, the polarized accumulation of RhoA appears to result from local inhibition by the astral microtubules of the anaphase spindle (Murthy and Wadsworth 2008; Tse et al. 2012). The inhibitory mechanism is not fully understood; however, one component involves local inhibition of anillin function by astral microtubules (Piekny and Glotzer 2008; Tse et al. 2011). These additional mechanisms confer robustness and could be particularly relevant in cleaving embryonic blastomeres.

Recently, the use of optogenetic tools in the context of cytokinesis revealed that spatial and temporal control of cytokinesis is largely achieved through the control of RhoA activation. Creation of a zone of active RhoA can induce furrow formation in cells at various cell cycle stages and irrespective of the position of the spindle (Wagner and Glotzer 2016). In certain animal cells, furrow formation is independent of spindle microtubules. Drosophila pole cells, which ultimately become germ cells, are formed by a budding-like process that encapsulates the germ cell nucleus (Cinalli and Lehmann 2013). This contractility depends on RhoA and its effectors, as well as on a protein called germ cell-less. An analogous process can be elicited in dividing Drosophila neuroblasts. Depolymerization of the spindle microtubules eliminates the conventional furrow, but a secondary furrow that requires cortical polarity proteins can occur in these cells at the onset of anaphase (Cabernard et al. 2010).

\subsection{Temporal Control of Cytokinesis in Fission Yeast}

In $S$. pombe, contractile ring assembly begins earlier in the cell cycle than in metazoan cells. The contractile ring assembles from equatorially positioned, cortically associated, cytokinetic nodes (large, membrane-associated multimo- 
M. Glotzer

lecular complexes). Cytokinetic nodes are derived from the fusion, during $\mathrm{G}_{2}$ phase, of two classes of interphase nodes that differ in protein composition, subcellular position, and mobility (Akamatsu et al. 2014). Components of the contractile ring join one of the two classes of cortical nodes at different times throughout the cell cycle (see below). Following association with class 1 nodes shortly after division, the anillin ortholog Mid1 ultimately concentrates in the equatorially localized cytokinetic nodes in $\mathrm{G}_{2}$ (Akamatsu et al. 2014). Myosin II is also recruited to these nodes before spindle assembly, and other factors, including a nucleator of actin filaments, are recruited during $M$ phase (Wu et al. 2003). Ring constriction begins $\sim 25 \mathrm{~min}$ after assembly of a complete contractile ring, which is $\sim 10 \mathrm{~min}$ after the spindle has fully elongated.

A signaling cascade called the septation initiation network (SIN) regulates both classes of interphase nodes and maturation of the contractile ring. The SIN includes a GTPase, scaffold proteins, and kinases from both the Ste20 and Ndr kinase families (see Simanis 2015 for review). This pathway becomes activated during anaphase and localizes prominently at spindle pole bodies (SPBs) (some components accumulate specifically on one of the two SPBs); the most-downstream components-the $\mathrm{Ndr}$ kinase Sid2 and its associated activating subunit Mob1localize to the contractile ring.
Mutations in SIN pathway components prevent complete ring assembly (Hachet and Simanis 2008), and the SIN regulates several contractile ring components. SIN activation promotes disassembly of type 1 nodes and maturation of type 2 nodes ( $\mathrm{Pu}$ et al. 2014). The SIN also regulates contractile ring components, including the formin Cdc12 and the F-BAR protein Cdc15. Cdc15 regulation by the SIN is likely indirect, as $\mathrm{Cdc} 15$ is activated by dephosphorylation. Indeed, the SIN activates the phosphatase Clp1, which dephosphorylates Cdc15 (Roberts-Galbraith et al. 2010). Dephosphorylation of Cdc15 allows its oligomerization, its association with the membrane, and allows it to interact with its binding partner Cdc12 (Fig. 2) (Roberts-Galbraith et al. 2010).

Not only is the SIN required for maturation of the contractile ring, its hyperactivation can induce contractile ring assembly and constriction at inappropriate times. Direct activation of the SIN (Schmidt et al. 1997), or its indirect activation by means of polo kinase Plol overexpression (Cullen et al. 2000; Tanaka et al. 2001), induces assembly of contractile rings and septa at various stages of the cell cycle. More downstream, overexpression of a truncated $\mathrm{Cdc} 12$ formin is also sufficient to induce ring assembly in interphase (Yonetani and Chang 2010). Because SIN activation promotes formin activation (Bohnert et al. 2013), these perturbations might share a common mechanistic basis.
A

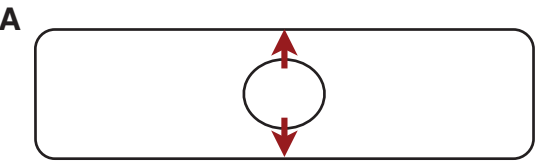

C

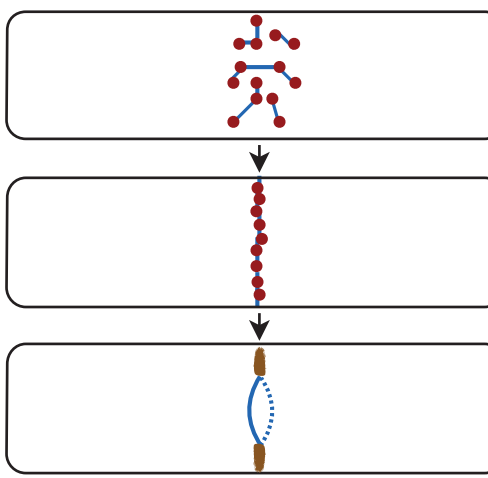

B

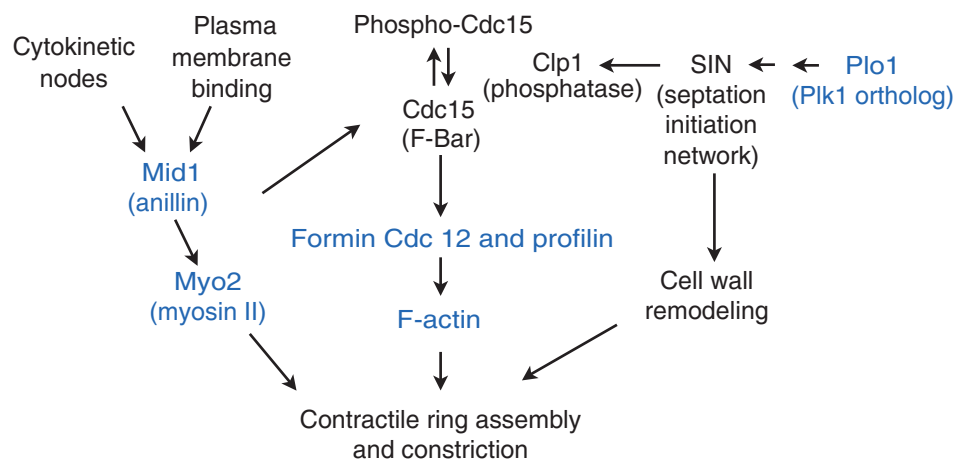

Mid1/Myo2/formin nodes

Actin filaments

Septal materials

Figure 2. Cytokinesis in the fission yeast Schizosaccharomyces pombe. (A) Overview of the mechanism of divisionplane positioning. The contractile ring assembles at a site that is determined by the position of the nucleus in $\mathrm{G}_{2}$ phase. Interphase microtubules serve to position the nucleus near the cell center. $(B)$ Pathway that induces accumulation of components of the contractile ring. Components conserved between yeast and metazoa are highlighted in blue. $(C)$ Schematic depicting the assembly of an actomyosin-based contractile ring from a broad band of cytokinetic nodes that progressively align by means of the so-called search-capture-pull-release mechanism. Note also the relationship between the ingressing contractile ring and the required remodeling of the cell wall materials through septum deposition. 


\subsection{Contractile Ring Positioning in Fission Yeast}

In fission yeast, as in metazoan cells, multiple pathways cooperate to position the division plane. These pathways for division-plane positioning converge on Mid1, an anillin-like scaffold protein. Deletion of Mid1, although not lethal, causes severe defects in ring positioning and assembly (Paoletti and Chang 2000). Mid1 has a cryptic C2 domain, a pleckstrin-homology $(\mathrm{PH})$ domain, and an amphipathic helix that permits it to associate directly with the membrane (Sun et al. 2015). Its membrane localization is regulated by several pathways (Almonacid et al. 2009; Lee and $\mathrm{Wu} 2012$ ). One pathway involves regulated export of Mid1 from the nucleus (Fig. 2A), promoting membrane association in the vicinity of the nucleus (Celton-Morizur et al. 2004; Lee and Wu 2012); an additional regulatory pathway involves the kinase Pom1, which regulates cell polarity and prevents Mid1 accumulation at cell tips (CeltonMorizur et al. 2006; Padte et al. 2006). A third pathway that controls Mid1 localization involves cortical nodes of proteins that accumulate during interphase. Two types of nodes accumulate during interphase in wild-type cells (Akamatsu et al. 2014). Type 1 nodes coordinate growth and the cell cycle (Moseley et al. 2009). These nodes are nucleated by the cell cycle-regulating kinase Cdr2 and recruit both Mid1 and myosin II. Type 2 nodes contain the adaptor protein Blt1 and a RhoGEF called RhoGEF2 (Moseley et al. 2009; Guzman-Vendrell et al. 2013). Type 1 nodes accumulate in the cell center, whereas type 2 nodes are more mobile. These two types of nodes fuse in late $G_{2}$ in the cell center, and some type 1 node components dissipate from these hybrid, cytokinetic nodes during $\mathrm{M}$ phase (Fig. 2C) (Guzman-Vendrell et al. 2013). Cytokinetic nodes, loaded with approximately 20 to 40 molecules of Mid2 and myosin II, recruit a small number of $\mathrm{Cdc} 12$ formin dimers, approximately 20 molecules of the F-BAR protein Cdc15, and other ring components (Wu and Pollard 2005; Laporte et al. 2011). These nodes then undergo a wellcharacterized ring assembly process that will be discussed below (Vavylonis et al. 2008). Mid1 likely induces local concentration of contractile ring components, as artificial targeting of several ring components to nodes can largely restore cytokinesis in mid1 mutant cells (Tao et al. 2014). This is likely to reflect a conserved function of the anillin family of scaffold proteins.

Despite their central role in cytokinesis, neither type of node appears essential for viability. Deletion of node components Cdr2, Blt1, and Gef2, either alone or in some pairwise combinations, delays, but does not prevent, contractile ring assembly (Almonacid et al. 2009; Moseley et al. 2009; Akamatsu et al. 2014; Goss et al. 2014). Contractile ring positioning in these cells is sensitive to perturbations that would otherwise have mild effects. This robustness could be due to the presence of additional cytokinetic regulators in the nodes, notably the nonessential RhoGEF Gef2 (Ye et al. 2012; Guzman-Vendrell et al. 2013). These results indicate that both types of nodes play a central role in ring assembly and make the process rapid, properly timed and robust to perturbations. However, the relatively mild phenotypes of mutants in both types of nodes suggest the existence of other mechanisms for contractile ring assembly.

Consistent with this model, contractile ring assembly in the related fission yeast Schizosaccharomyces japonicus does not require Mid1 (Gu et al. 2015). When Mid1 is absent, myosin II does not detectably accumulate on cortical nodes during interphase-it first appears in anaphase. Therefore a robust, Mid1-independent pathway exists in this species; the aforementioned kinase Pom1 plays a key role in ring positioning (Gu et al. 2015).

\subsection{Bud Site Selection in Budding Yeast}

The spatial control of cytokinesis in budding yeast is directly coupled to bud site selection, as cell division occurs at the bud neck (Fig. 3A). During mitosis and anaphase, one of the two spindle poles, usually the older one, is drawn through the bud neck to coordinate mitosis with the plane of cell division. Despite the fact that the spindle moves relative to the plane of cell division rather than the converse in metazoa, conceptual commonalities exist between the process of bud site selection in yeast and division-plane positioning in metazoan cells. Both processes involve local accumulation of an activated Rho-family GTPase, which in yeast budding is Cdc42 (see Bi and Park 2012 for review). This is accomplished by the cell cycle-regulated activation and localization of a GEF, which in yeast is Cdc24. Local accumulation of $\mathrm{Cdc} 42$ at a cortical site in $\mathrm{G}_{1}$ phase promotes assembly of septin rings at the bud neck, through adaptor proteins. Ultimately, septin filaments template assembly of the contractile ring by recruiting specific factors at defined cell cycle stages.

\subsection{Temporal Control of Cytokinesis in Budding Yeast}

Contractile ring assembly appears to initiate early in the cell cycle in budding yeast, as myosin II accumulates at the bud neck during $G_{1}$ phase. However, two sequential and independent pathways promote myosin accumulation to this site: One pathway is active during $G_{1}$, and the second is active during anaphase; only the latter is required for cytokinesis (Fang et al. 2010). Other important events in ring assembly are temporally regulated by a polo kinase ortho$\log$, Cdc5. Cdc5 promotes accumulation of the RhoGEF 
A

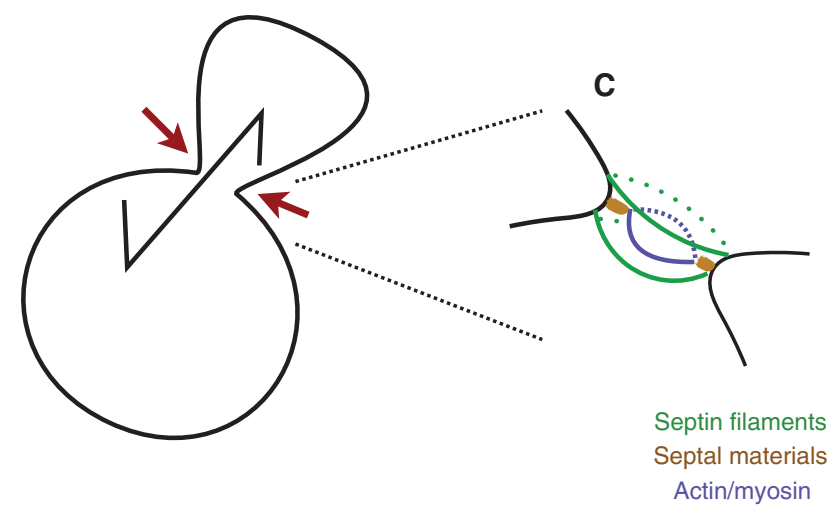

B

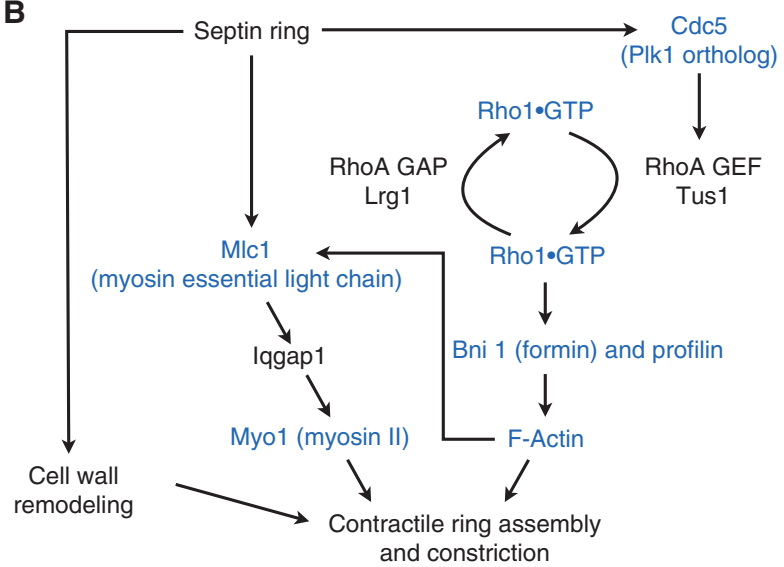

Figure 3. Cytokinesis in the budding yeast Saccharomyces cerevisiae. (A) Overview of the mechanism of divisionplane positioning. The contractile ring assembles at the neck of the bud, which is positioned in early $\mathrm{G}_{1}$ phase. The spindle is positioned relative to the bud neck during anaphase. (B) Pathway that induces accumulation of components of the contractile ring. Components conserved between metazoa and yeast are highlighted in blue. $(C)$ Spatial organization of the yeast contractile ring, highlighting the relationship between the ingressing contractile ring and the required remodeling of the cell wall materials through septum deposition. GAP, GTPase-activating protein; GEF, GDP-GTP exchange factor.

Tus1 at the bud neck shortly after anaphase (Yoshida et al. 2006). Tus1, in turn, activates Rho1, inducing local recruitment of the formin Bnil, which nucleates assembly of the actin filaments in the contractile ring (Fig. 3B,C).

\subsection{Spatiotemporal Regulation-Summary}

Although diverse, the examples above do not encompass all the known mechanisms for division-plane positioning in eukaryotic cells. Plant cell cytokinesis diverges significantly, and other organisms, such as protozoa, divide through distinct mechanisms (Farr and Gull 2012). However, despite this diversity, a number of themes recur. First, redundant pathways ensure proper positioning in many cells. Second, lipid binding, multiprotein scaffolds recruit the structural proteins of the contractile ring. Third, pololike kinases play a major role in promoting cytokinetic events, although their substrates vary between organisms. Fourth, there is an inverse correlation between the degree of order of the structure that templates the division plane and the degree of flexibility in the division-plane positioning mechanism. For example, the septin ring that organizes the contractile ring of budding yeast is highly ordered and stable at the bud neck, and this is the only site at which cytokinesis occurs in this organism. The nodes and nucleus of fission yeast that position the division plane are moderately mobile and allow the division plane to be positioned relative to the position of the cell nucleus. In animal cells, division-plane positioning is highly plastic and allows repositioning after its initial assembly (Rappaport 1985). It lacks large structures or stable aggregates, yet each compo- nent of the multiprotein complex that positions the contractile ring has membrane-binding motifs, suggesting cooperative membrane association.

\section{CONTRACTILE RING ASSEMBLY AND CONSTRICTION}

Once the upstream pathways induce accumulation of contractile ring components at the equatorial cortex, they then assemble into a ring that constricts and deforms the overlying plasma membrane. This process involves assembly of bundles of actomyosin, coordinated constriction, and filament disassembly, and dynamic, yet force-generating, association of contractile bundles with the membrane. Many of the key proteins - cytoplasmic myosin, actin, formin, actin-bundlers, the actin-depolymerizing factor cofilin, and anillin-accumulate on contractile rings in metazoa and budding and fission yeast, suggesting that the underlying assembly process is generally conserved. However, they are not yet fully understood.

\subsection{The Role of RhoA and Its Effectors in Metazoa}

Activated Ect2 generates a metastable cortical zone of active RhoA, likely through positive feedback (Zhang and Glotzer 2015). Active RhoA directly stimulates the Rho kinase ROCK, which induces myosin light chain phosphorylation, filament assembly, and motor activation (Kosako et al. 2000). RhoA also directly activates formins, which nucleate assembly of unbranched actin filaments (Otomo et al. 2005; Watanabe et al. 2008, 2013). RhoA recruits anillin, 
a scaffold protein that can interact with RhoA, F-actin, and myosin (Fig. 1B) (Straight et al. 2005; Piekny and Glotzer 2008; Sun et al. 2015). These direct RhoA effectors generate myosin minifilaments and actin filaments that recruit tropomyosin, $\alpha$-actinin (Mukhina et al. 2007), and septin. The process by which these components assemble into a well-ordered ring is not fully understood, in part, because the underlying events involve rapidly rearranging and highly concentrated assemblages of filaments that are challenging to resolve in the light microscope.

\subsection{Membrane Association of the Contractile Ring}

The creation of a furrow that partitions the daughter cells requires association of the contractile ring with the plasma membrane. Note that the contractile ring need not encircle the cell for furrow ingression to occur as there are numerous examples of unilateral furrowing in which the furrow ingresses from one side before it is fully assembled, including in amphibians and other species. This indicates that membrane association of filaments in the contractile ring can support force generation. The nature of this association is not well characterized. Defects in this linkage would result in contractile ring constriction accompanied by a failure to draw in the plasma membrane.

There are some molecules that appear to contribute to this bridging function. Manipulation of the levels of phosphatidylinositol $(4,5)$-bisphosphate (PIP2) disrupts the association of the ring with the membrane in a minority of cells (Field et al. 2005). Lipid kinases and phosphatases responsible for controlling PIP2 levels impact cytokinesis at a variety of stages (Ben El Kadhi et al. 2011; Dambournet et al. 2011). The complete list of relevant PIP2-binding factors has not been unambiguously identified, although a class of good candidates is FERM (4.1 protein-ezrinradixin-moesin)-domain-containing proteins (Fehon et al. 2010). In Dictyostelium, cells deficient in the FERMdomain-containing protein talin show compromised linkage between the ring and membrane (Tsujioka et al. 2012); ERM proteins also suppress cortical blebbing during cytokinesis, particularly at cell poles (Roubinet et al. 2011). In both S. pombe and Drosophila, F-BAR-containing proteins might serve as linkers between the membrane and cytoskeleton (Roberts-Galbraith et al. 2010; Takeda et al. 2013); in S. pombe, the F-BAR protein Cdc15 also promotes accumulation of a polysaccharide synthetase (Arasada and Pollard 2014), which also contributes to productive furrowing (Liu et al. 1999). Cytoplasmic myosin II associates with anionic phospholipids ( $\mathrm{Li}$ et al. 1994). Thus, there might not be a single, specific tether for the contractile ring, but rather a constellation of diverse contributing factors. Finally, late in cytokinesis, the membrane-binding $\mathrm{C} 1$ domain of the centralspindlin subunit $\mathrm{Cyk} 4$ is required for membrane linkage to the central spindle at the midbody stage (Lekomtsev et al. 2012), which is also stabilized by the scaffold protein anillin (D'Avino et al. 2008; Kechad et al. 2012).

\subsection{Contractile Ring Assembly in Fission Yeast}

The process of ring assembly has been most clearly defined in fission yeast. The aforementioned nodes that contain myosin and formin nucleate actin filaments that are captured by neighboring nodes and pulled together (Vavylonis et al. 2008). The barbed end of the growing actin filament is anchored by the nucleating formin at the donor node, and the pointed end of the filament is captured by myosin at the acceptor node (Laporte et al. 2011). This interaction results in node congression at $\sim 30 \mathrm{~nm} / \mathrm{sec}$ for a duration of $\sim 20 \mathrm{sec}$. Internode connections are severed by cofilin (Chen and Pollard 2011), and this process repeats until the nodes and filaments are aligned. This is known as the search-capture-pull-release model (Fig. 2C) (Vavylonis et al. 2008). This process has been modeled using physiological parameters that recapitulate observations in wildtype and mutant conditions. Some F-actin in the ring is recruited from filaments that assemble at peripheral sites of nucleation (Huang et al. 2012). However, as discussed previously, other mechanisms might suffice for functional ring assembly in fission yeast.

\subsection{Myosin Function during Cytokinesis}

Ever since actin and nonmuscle myosin II were identified as important components of the contractile ring (Carter 1967; Schroeder 1968; Fujiwara and Pollard 1976; Mabuchi and Okuno 1977), the prevailing model for the process of constriction has involved myosin-II-mediated sliding of actin filaments. In a wide variety of cell types, including mammalian cells, Drosophila, C. elegans, and fission yeast, nonmuscle myosin II is required for successful cytokinesis. Myosin V can contribute to cytokinesis in S. pombe (Laplante et al. 2015). The situation in mammals is complicated by genetic redundancy because of multiple isoforms of nonmuscle myosin II that show partial overlap among isoforms in certain tissues (Takeda et al. 2003; Conti et al 2004; Bao et al. 2005; Ma et al. 2010). Nevertheless, there is strong evidence that supports a role for myosin II motor activity in cytokinesis.

However, myosin II is not invariably required for cytokinesis. Notable exceptions include plants, which lack nonmuscle myosin II altogether, and Dictyostelium, in which adherent-although not detached — cells have a myosin-IIindependent pathway for cytokinesis (Neujahr et al. 1997; Zang et al. 1997). In budding yeast, there is clear evidence 
that myosin performs functions other than filament sliding in cytokinesis. Remarkably, the requirement for Myol can be provided by a headless version lacking the motor domain. This truncated myosin is therefore not performing a filament-cross-linking function-more likely it functions as a scaffold that guides deposition of septal materials (Lord et al. 2005; Fang et al. 2010; Wloka et al. 2013). Although headless myosin fulfills its essential function, loss of the head has consequences-for example, the motor domain of myosin is needed to accelerate ring constriction and the rate of actin disassembly during constriction (Mendes Pinto et al. 2012). Models for force generation have been compared and contrasted in a recent review (Mendes Pinto et al. 2013).

\subsection{Constriction of the Contractile Ring}

A number of factors influence furrow ingression during cytokinesis, including active force generators at the cleavage furrow, active protrusion at cell poles, overall cortical tension, the viscoelasticity of the cytoplasm, and interactions of the cell with its environment (Poirier et al. 2012). Most cells round up during mitosis, and cell cycle-regulated changes in cortical tension have been measured. However, the timing of these changes during mitosis is not consistent across species (Hiramoto 1990; Ramanathan et al. 2015).

Contractile rings in marine invertebrate blastomeres exert forces on the order of 1-10 nN (Rappaport 1967; Hiramoto 1975). Contractile rings in fission yeast, in contrast, show much smaller forces, although these contractile rings are much smaller in cross section than those of marine invertebrate blastomeres. However, the two types of rings generate similar tensions, on the order of $10 \mathrm{nN} /$ $\mu \mathrm{m}^{2}$ (Stachowiak et al. 2014). As has been extensively discussed, ring ingression in these cells requires myosin motor activity, and sufficient motors are present in the fission yeast ring to generate these forces, assuming that the actin filaments are properly oriented (Wu and Pollard 2005; Stachowiak et al. 2014).

In sea urchin embryos, contractile ring width and thickness remain fairly constant during constriction, reflecting significant disassembly of actin filaments as it constricts (Schroeder 1972). Observations of fluorescently tagged myosin indicate that, although the total number of myosin motors decreases as the ring constricts, the local concentration can increase severalfold or remain relatively constant in fission yeast or C. elegans blastomeres, respectively (Wu and Pollard 2005; Carvalho et al. 2009).

The slime mold Dictyostelium provides a clear example of an alternative means of force generation in the furrow. Although myosin II is essential for furrow formation in such cells when grown in suspension (De Lozanne and
Spudich 1987), knockout cells divide with nearly normal kinetics when allowed to attach to the substrate (Neujahr et al. 1997). Nonuniform changes in cortical tension and hydrodynamic pressures can account for furrowing in such cells (Poirier et al. 2012).

\subsection{Septum Deposition in Yeast}

Although constriction of the contractile ring is largely driven by the actomyosin-based contractile ring in metazoan cells, in budding yeast, regulated secretion of cell wall material makes a significant contribution (Figs. 2C and 3C). Indeed, in budding yeast, deletion of the gene encoding myosin II is tolerated in some strain backgrounds. Proteins that act in a parallel pathway to actomyosin contractility would be predicted to be essential in cells that lack myosin. Hof1, which is related to the fission yeast F-BAR protein Cdc15, fits these criteria (Vallen et al. 2000). Hof1 binds to chitin synthase II, which is essential for secretion of primary septum material. Hof1 also binds to the tail of yeast myosin II, suggesting that Hof1 coordinates the contractile ring and the enzyme crucial for cell wall deposition (Oh et al. 2013). Similar interactions exist in fission yeast. Thus, in fungi, the contractile ring could function to guide deposition of septal material (Zhou et al. 2015).

\section{RECONSTITUTION OF THE CONTRACTILE APPARATUS}

Aspects of cytokinesis have been reconstituted in a number of in vitro systems. Contractile ring constriction has been shown in both permeabilized vertebrate cells (HoffmanBerling 1954; Cande 1980) and isolated contractile rings (Mabuchi et al. 1988). Actin-filament-stabilizing drugs inhibit ring constriction; thus, constriction depends on actin filament disassembly. This approach has received renewed attention in budding and fission yeast (Young et al. 2010; Mishra et al. 2013). In the former case, ring constriction occurs in the presence of cytoplasmic extracts (Young et al. 2010). In S. pombe, constriction occurs in permeabilized cells largely devoid of cytoplasmic components (Mishra et al. 2013). During constriction of the ring, myosin II becomes progressively concentrated, whereas a significant portion of the filamentous actin disassembles. However, in this case, stabilization of actin filaments does not impair ring constriction. The genetic tractability of this system should permit dissection of this important step in cytokinesis.

The spatially regulated signaling events of cytokinesis have been reconstituted in unfractionated Xenopus egg extracts on supported lipid bilayers (Nguyen et al. 2014). In this system, microtubules polymerized from neighboring 
synthetic asters interact, forming discrete overlap zones that recruit central spindle components in a manner dependent on aurora B kinase. These zones induce RhoA activation in the adjacent membrane.

Cytokinesis-like events have also been modeled in a fully defined system, producing striking results (Miyazaki et al. 2015). Actin polymerization in phospholipid-delimited aqueous droplets in oil results in assembly of filament bundles that encircle the droplets. Successful ring formation requires the droplet diameter to be smaller than the persistence length of single actin filaments $(\sim 5-15 \mu \mathrm{m})$. Actin polymerization in the presence of double-headed heavy meromyosin fragments generated constricting rings. The constriction rate is proportional to ring size, similar to that seen in C. elegans embryos (Carvalho et al. 2009). During constriction, the rings slide along the inner leaflet of the droplet, rather than inducing deformations, as seen in permeabilized fission yeast and spheroplasts (Mishra et al. 2013; Stachowiak et al. 2014). Importantly, ring constriction under these conditions depends on motor activity_rigor conditions impair the assembly of rings seen in the absence of myosin. Thus, some characteristic features of the contractile ring can be solely attributed to interactions between spatially constrained actin filaments and myosin motor proteins.

\section{ABSCISSION}

Following cleavage furrow ingression, dividing cells still need to resolve the single membrane that encapsulates the two nascent daughter cells, a process known as abscission (see Mierzwa and Gerlich 2014 for review). This process is topologically similar to viral budding and formation of multivesicular bodies, in which the neck of the constriction is exposed to extracellular space, as compared with endocytosis, in which the neck is exposed to the cytoplasm (Carlton and Martin-Serrano 2007). This requires that cytoplasmic machinery that drives membrane scission must be specialized to constrict the membrane without sterically interfering with membrane scission. These processes are mediated by a protein complex, called "endosomal sorting complex required for transport III" (ESCRT-III), that assembles into a spiral arrangement of filaments that associates with the cytoplasmic face of the plasma membrane and induces membrane deformation (Fig. 4) (see Henne et al. 2011 and Agromayor and Martin-Serrano 2013 for review).

\subsection{Evolutionary Conservation of ESCRT-III}

The ESCRT-III complex contains four structurally related subunits, called charged multivesicular body proteins (CHMPs), each of which can polymerize on an appropriate membrane (Shim et al. 2007). However, in vivo and in vitro, the four subunits have distinct functions. CHMP6/ Vps20 is thought to nucleate assembly of longer CHMP4/ Snf7 polymers that are terminated by CHMP3/Vps24 and CHMP2/Vps2 (Teis et al. 2008; Wollert et al. 2009). The two terminal ESCRT-III subunits induce a conformational change in the CHMP4/Snf7 polymers, promoting membrane deformation. They also recruit an AAA-ATPase complex, Vps4, that disassembles and recycles ESCRT-III components (see Mierzwa and Gerlich 2014 for review). Abscission timing is closely linked to recruitment of Vps4 (Elia et al. 2011).

The ESCRT-III complex could be one of the most ancient cytokinesis factors as it is found not only in eukaryotes but also in some archaea. The archaea contains multiple phyla, including the well-characterized Crenarchaeota and Euryarchaeota. Genomic comparisons of these two phyla suggest that they use distinct molecular mechanisms for cell division. Like many eubacterial species, many Euryarchaeota species contain FtsZ, a tubulin-related protein that participates in cell division. However, FtsZ is lacking in many Crenarchaeota species. These species do, however, contain $\mathrm{CdvB}$, which is related to ESCRT-III subunits (Lindås et al. 2008), and $\mathrm{CdvC}$, which is related to the Vps4 AAA-ATPase that promotes disassembly of ESCRT-III filaments. $C d v$ genes are induced before cell division, and the $\mathrm{Cdv}$ proteins accumulate between segregated nucleoids (Lindås et al. 2008; Samson et al. 2008). Overexpression of an ATPase-defective variant of $\mathrm{CdvC}$ prevents cell division, providing functional evidence for its role in cell division. Thus, the involvement of ESCRTIII proteins in eukaryotic cell division likely reflects an ancient role. Intriguingly, related proteins are also found in Lokiarchaeota, an archaeal phylum that also contain proteins similar to eukaryotic actin and GTPases (Spang et al. 2015).

Despite this strong evolutionary connection and the compelling evidence for its role in mammalian cells, there is limited evidence implicating the ESCRT-III complex in cytokinesis in other model organisms. For example, in C. elegans, depletion of various ESCRT subunits affects endocytosis and other process-however, it does not cause defects in cytokinesis (Kim et al. 2011). Residual ESCRT-III subunits might obscure a role for this machinery in cytokinesis. In Drosophila, ESCRT-III subunits accumulate at the midbody, but a functional role in cytokinesis has not yet been shown (Capalbo et al. 2012). Interestingly, in budding yeast, in which the ESCRT system was first characterized, ESCRT-III subunits are not essential; however, there are weak genetic interactions with mutations in known cytokinesis genes, including genes encoding septins (McMurray et al. 2011). Septal deposition might provide an 
M. Glotzer

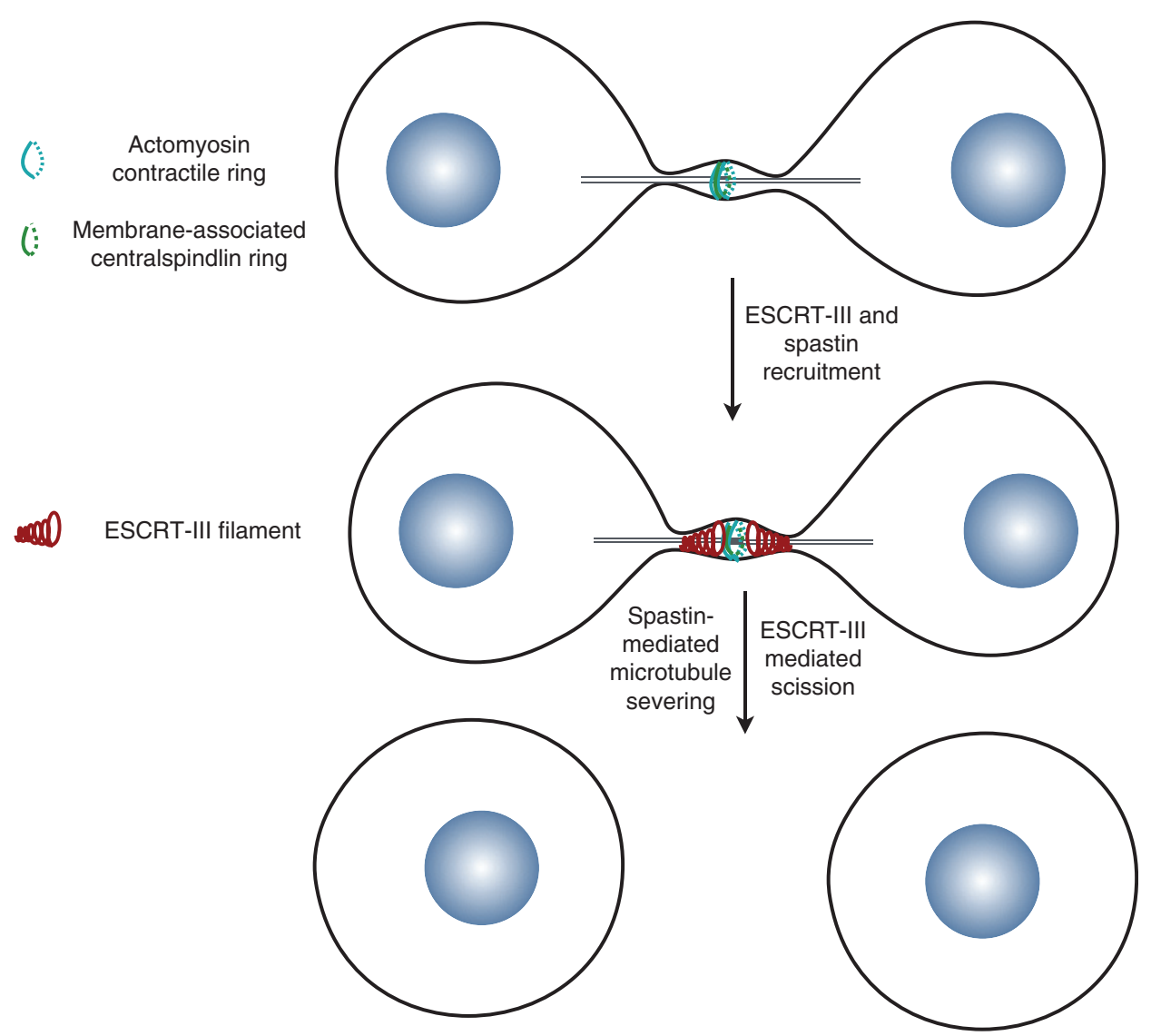

Figure 4. Abscission in metazoa. Cell separation is mediated by endosomal sorting complex required for transport III (ESCRT-III) filaments that assemble in constriction zones that flank the centralspindlin-dense midbody. The remaining microtubules are depolymerized by spastin, and the membrane scission process itself is driven by ESCRT-III filaments that constrict the neck of the cytoplasmic bridge between the two daughter cells.

alternative means to drive final constriction of the neck of the cell.

\subsection{ESCRT-III Recruitment}

Recruitment of ESCRT-III to the cytoplasmic bridge in mammalian cells requires centralspindlin and an interacting adaptor protein, Cep55 (Zhao et al. 2006), which in turn recruits two additional adaptors, Alix and the ESCRTI subunit TSG101 (Carlton and Martin-Serrano 2007; Morita et al. 2007; Lee et al. 2008). Alix and TSG101 directly recruit CHMP4 subunits of the ESCRTIII complex (McCullough et al. 2008). CHMP4 accumulates in filaments at regions of secondary constrictions that flank the central midbody (Guizetti et al. 2011). For these secondary constrictions to proceed to completion, microtubules in the midbody must be removed as they obstruct the intercellular bridge. ESCRT-III directs recruitment of the microtubule-severing complex spastin by means of CHMP1B, a peripheral subunit of the ESCRT-III complex (Yang et al. 2008).

\subsection{Regulation of Abscission}

The numerous steps required for abscission provide opportunities for regulation. Chromatin stuck in the midbody prevents or delays completion of cytokinesis (Mendoza et al. 2009; Steigemann et al. 2009). This delay involves activation of the chromosome passenger complex by the trapped DNA, causing midbody stabilization (Steigemann et al. 2009). Aurora B phosphorylates CHMP4C (Capalbo et al. 2012; Carlton et al. 2012), which delays abscission, perhaps by acting as an inhibitor of the CHMP4B isoform. This model is based on the finding that CHMP4C is not essential for cytokinetic abscission-in fact, it acts as an inhibitor of the process (Carlton et al. 2012).

The cellular microenvironment impacts the timing of abscission. The time interval between formation of the midbody and abscission is highly variable. Some variability might be due to the variable rate of daughter cell spreading that exerts tension on the intercellular bridge. Counterintuitively, increased tension on the bridge induces a delay in abscission (Lafaurie-Janvore et al. 2013). Experimentally 
severing one side of an intercellular bridge under tension releases the tension and induces rapid severing on the other side of the bridge. Recruitment of ESCRT-III subunits is tension sensitive, providing a possible underlying molecular mechanism.

\subsection{Fate of Midbody Remnants}

Once the two daughter cells fully separate, a portion of the cytoplasmic bridge or midbody remains. In principle, the structure could be internalized into autophagosomes directly, released into the extracellular milieu, or the particle could be later phagocytosed by the dividing cell or its neighbors and ultimately degraded by lysosomal processes (Crowell et al. 2014). The balance between these fates varies in a cell type-dependent manner (Ettinger et al. 2011). Division remnants have been suggested to alter cellular behavior (Ettinger et al. 2011; Kuo et al. 2011), but the perturbations used to alter the fate of internalized midbodies might have indirect effects (Crowell et al. 2014).

\section{CONTEXT DEPENDENCE OF CYTOKINETIC MECHANISMS}

It is tempting to posit that cytokinesis is a singular event that is largely similar in animal cells and fungi. Indeed, there are common requirements that appear in many organisms and cell types. However, it is not difficult to find different mechanisms in different species. In fact, the requirements for cytokinesis vary within a given organism, depending on the cellular context. For example, during the cleavage stages of embryogenesis, when cells divide without growing, cell size changes over multiple orders of magnitude, and there are likely to be adaptations required for division of large blastomeres. Indeed, in aqueous droplets that reconstitute contractile rings, droplet flattening, or myosin addition increases the size of the droplets that assemble intact rings (Miyazaki et al. 2015). Several Drosophila mutants show spermatocyte-specific cytokinesis defects, providing additional evidence for context-dependent requirements (Giansanti et al. 2004). Likewise, in Drosophila, septins are essential for division of epithelial cells that divide in the plane of the epithelia, but not those that divide in the orthogonal plane (Founounou et al. 2013). Similarly, as contractile rings ingress against cortical tension, defects in force generation in the ring might be compensated by reductions in cortical tension. In C. elegans, mutations in CYK-4 that limit RhoA activation can be partially suppressed by mutations in Arp $2 / 3$ or its activator Rac1 (Canman et al. 2008; Loria et al. 2012).

Abscission regulators also show cell-type-specific requirements. For example, the RhoA-activated kinase citron
(Gai et al. 2011) contributes to abscission in cultured cells, but its requirement is tissue specific in vivo. Mice possessing a mutant citron kinase are grossly normal at birth, but they show postnatal neurological defects (Di Cunto et al. 2000). Multinucleate cells are observed at low frequency specifically in the brain; this could result from differential clearance of multinucleate cells. However, it seems more likely that the cytokinetic requirement for citron depends on growth conditions. Thus, the mechanical or biochemical properties of a cell or tissue can influence the genetic requirements for cytokinesis.

\section{CONCLUSION}

Despite the remarkable progress in defining the molecular mechanism of cytokinesis, much remains to be learned about this essential cellular process. The mechanism by which the contractile ring assembles, constricts, and generates force remains quite opaque in many systems. Likewise, there are open questions concerning the mechanism and regulation of membrane abscission. Finally, accumulating results show that, despite significant shared components and mechanisms, different cells and tissues of a given organism have specific requirements for cytokinesis owing to differences in cell size, cellular microenvironment, or the panoply of biochemical regulators. The number of such variations increases when multiple species are considered. Thus, it is crucial to consider the cellular context when studying cytokinesis. Our understanding of cytokinesis in intact tissues and animals is particularly limited. Last, some subtle cytokinetic defects could affect particular cell types and result in disease (Liljeholm et al. 2013).

\section{ACKNOWLEDGMENTS}

I thank Jian-Qiu Wu, David Kovar, Ed Munro, and Tom Pollard for comments and discussion. This work was supported by National Institutes of Health (NIH) grant R01GM85087.

\section{REFERENCES}

Adl SM, Simpson AGB, Lane CE, Lukeš J, Bass D, Bowser SS, Brown MW, Burki F, Dunthorn M, Hampl V, et al. 2012. The revised classification of eukaryotes. J Eukaryot Microbiol 59: 429-493.

Agromayor M, Martin-Serrano J. 2013. Knowing when to cut and run: Mechanisms that control cytokinetic abscission. Trends Cell Biol 23: 433-441.

Akamatsu M, Berro J, Pu K-M, Tebbs IR, Pollard TD. 2014. Cytokinetic nodes in fission yeast arise from two distinct types of nodes that merge during interphase. J Cell Biol 204: 977-988.

Almonacid M, Moseley JB, Janvore J, Mayeux A, Fraisier V, Nurse P, Paoletti A. 2009. Spatial control of cytokinesis by Cdr2 kinase and Mid1/anillin nuclear export. Curr Biol 19: 961-966. 
Arasada R, Pollard TD. 2014. Contractile ring stability in S. pombe depends on F-BAR protein Cdc15p and Bgslp transport from the Golgi complex. Cell Rep 8: 1533-1544.

Bao J, Jana SS, Adelstein RS. 2005. Vertebrate nonmuscle myosin II isoforms rescue small interfering RNA-induced defects in COS-7 cell cytokinesis. J Biol Chem 280: 19594-19599.

Basant A, Lekomtsev S, Tse YC, Zhang D, Longhini KM, Petronczki M, Glotzer M. 2015. Aurora B kinase promotes cytokinesis by inducing centralspindlin oligomers that associate with the plasma membrane. Dev Cell 33: 204-215.

Ben El Kadhi K, Roubinet C, Solinet S, Emery G, Carréno S. 2011. The inositol 5-phosphatase dOCRL controls $\mathrm{PI}(4,5) \mathrm{P}_{2}$ homeostasis and is necessary for cytokinesis. Curr Biol 21: 1074-1079.

Bezanilla M, Wilson JM, Pollard TD. 2000. Fission yeast myosin-II isoforms assemble into contractile rings at distinct times during mitosis. Curr Biol 10: 397-400.

Bi E, Park H-O. 2012. Cell polarization and cytokinesis in budding yeast. Genetics 191: 347-387.

Bi E, Maddox P, Lew DJ, Salmon ED, McMillan JN, Yeh E, Pringle JR. 1998. Involvement of an actomyosin contractile ring in Saccharomyces cerevisiae cytokinesis. J Cell Biol 142: 1301-1312.

Bohnert KA, Grzegorzewska AP, Willet AH, Vander Kooi CW, Kovar DR, Gould KL. 2013. SIN-dependent phosphoinhibition of formin multimerization controls fission yeast cytokinesis. Genes Dev 27: 21642177.

Burkard ME, Maciejowski J, Rodriguez-Bravo V, Repka M, Lowery DM, Clauser KR, Zhang C, Shokat KM, Carr SA, Yaffe MB, et al. 2009. Plk1 self-organization and priming phosphorylation of HsCYK-4 at the spindle midzone regulate the onset of division in human cells. PLoS Biol 7: e1000111.

Byers B, Goetsch L. 1976. A highly ordered ring of membrane-associated filaments in budding yeast. J Cell Biol 69: 717-721.

Cabernard C, Prehoda KE, Doe CQ. 2010. A spindle-independent cleavage furrow positioning pathway. Nature 467: 91-94.

Cande WZ. 1980. A permeabilized cell model for studying cytokinesis using mammalian tissue culture cells. J Cell Biol 87: 326-335.

Canman JC, Lewellyn L, Laband K, Smerdon SJ, Desai A, Bowerman B, Oegema K. 2008. Inhibition of Rac by the GAP activity of centralspindlin is essential for cytokinesis. Science 322: 1543-1546.

Capalbo L, Montembault E, Takeda T, Bassi ZI, Glover DM, D'Avino PP. 2012. The chromosomal passenger complex controls the function of endosomal sorting complex required for transport-III Snf7 proteins during cytokinesis. Open Biol 2: 120070.

Carlton JG, Martin-Serrano J. 2007. Parallels between cytokinesis and retroviral budding: A role for the ESCRT machinery. Science 316: $1908-1912$.

Carlton JG, Caballe A, Agromayor M, Kloc M, Martin-Serrano J. 2012. ESCRT-III governs the Aurora B-mediated abscission checkpoint through CHMP4C. Science 336: 220-225.

Carter SB. 1967. Effects of cytochalasins on mammalian cells. Nature 213: $261-264$.

Carvalho A, Desai A, Oegema K. 2009. Structural memory in the contractile ring makes the duration of cytokinesis independent of cell size. Cell 137: 926-937.

Celton-Morizur S, Bordes N, Fraisier V, Tran PT, Paoletti A. 2004. Cterminal anchoring of mid $1 \mathrm{p}$ to membranes stabilizes cytokinetic ring position in early mitosis in fission yeast. Mol Cell Biol 24: 1062110635.

Celton-Morizur S, Racine V, Sibarita J-B, Paoletti A. 2006. Pom1 kinase links division plane position to cell polarity by regulating Midlp cortical distribution. J Cell Sci 119: 4710-4718.

Chen Q, Pollard TD. 2011. Actin filament severing by cofilin is more important for assembly than constriction of the cytokinetic contractile ring. J Cell Biol 195: 485-498.

Cinalli RM, Lehmann R. 2013. A spindle-independent cleavage pathway controls germ cell formation in Drosophila. Nat Cell Biol 15: 839-845.
Conti MA, Even-Ram S, Liu C, Yamada KM, Adelstein RS. 2004. Defects in cell adhesion and the visceral endoderm following ablation of nonmuscle myosin heavy chain II-A in mice. J Biol Chem 279: 4126341266.

Cooke CA, Heck MM, Earnshaw WC. 1987. The inner centromere protein (INCENP) antigens: Movement from inner centromere to midbody during mitosis. J Cell Biol 105: 2053-2067.

Crowell EF, Gaffuri A-L, Gayraud-Morel B, Tajbakhsh S, Echard A. 2014. Midbody remnant engulfment after cytokinesis abscission in mammalian cells. J Cell Sci 127: 3840-3851.

Cullen CF, May KM, Hagan IM, Glover DM, Ohkura H. 2000. A new genetic method for isolating functionally interacting genes: High $p l o 1^{+}$-dependent mutants and their suppressors define genes in mitotic and septation pathways in fission yeast. Genetics 155: 1521 1534 .

Dambournet D, Machicoane M, Chesneau L, Sachse M, Rocancourt M, Marjou El A, Formstecher E, Salomon R, Goud B, Echard A. 2011. Rab35 GTPase and OCRL phosphatase remodel lipids and F-actin for successful cytokinesis. Nat Cell Biol 13: 981-988.

D'Avino PP, Takeda T, Capalbo L, Zhang W, Lilley KS, Laue ED, Glover DM. 2008. Interaction between Anillin and RacGAP50C connects the actomyosin contractile ring with spindle microtubules at the cell division site. J Cell Sci 121: 1151-1158.

De Lozanne A, Spudich JA. 1987. Disruption of the Dictyostelium myosin heavy chain gene by homologous recombination. Science 236: 10861091.

Demay BS, Bai X, Howard L, Occhipinti P, Meseroll RA, Spiliotis ET, Oldenbourg R, Gladfelter AS. 2011. Septin filaments exhibit a dynamic, paired organization that is conserved from yeast to mammals. J Cell Biol 193: 1065-1081.

Di Cunto F, Imarisio S, Hirsch E, Broccoli V, Bulfone A, Migheli A, Atzori C, Turco E, Triolo R, Dotto GP, et al. 2000. Defective neurogenesis in citron kinase knockout mice by altered cytokinesis and massive apoptosis. Neuron 28: 115-127.

Douglas ME, Davies T, Joseph N, Mishima M. 2010. Aurora B and 14-3-3 coordinately regulate clustering of centralspindlin during cytokinesis. Curr Biol 20: 927-933.

Elia N, Sougrat R, Spurlin TA, Hurley JH, Lippincott-Schwartz J. 2011. Dynamics of endosomal sorting complex required for transport (ESCRT) machinery during cytokinesis and its role in abscission. Proc Natl Acad Sci 108: 4846-4851.

Ettinger AW, Wilsch-Bräuninger M, Marzesco A-M, Bickle M, Lohmann A, Maliga Z, Karbanová J, Corbeil D, Hyman AA, Huttner WB. 2011. Proliferating versus differentiating stem and cancer cells exhibit distinct midbody-release behaviour. Nat Commun 2: 503.

Fang X, Luo J, Nishihama R, Wloka C, Dravis C, Travaglia M, Iwase M, Vallen EA, Bi E. 2010. Biphasic targeting and cleavage furrow ingression directed by the tail of a myosin II. J Cell Biol 191: 1333-1350.

Farr H, Gull K. 2012. Cytokinesis in trypanosomes. Cytoskeleton 69: 931 941.

Fehon RG, McClatchey AI, Bretscher A. 2010. Organizing the cell cortex: The role of ERM proteins. Nat Rev Mol Cell Biol 11: 276-287.

Field SJ, Madson N, Kerr ML, Galbraith KA, Kennedy CE, Tahiliani M, Wilkins A, Cantley LC. 2005. PtdIns $(4,5) \mathrm{P}_{2}$ functions at the cleavage furrow during cytokinesis. Curr Biol 15: 1407-1412.

Founounou N, Loyer N, Le Borgne R. 2013. Septins regulate the contractility of the actomyosin ring to enable adherens junction remodeling during cytokinesis of epithelial cells. Dev Cell 24: 242-255.

Frédéric MY, Lundin VF, Whiteside MD, Cueva JG, Tu DK, Kang SYC, Singh H, Baillie DL, Hutter H, Goodman MB, et al. 2013. Identification of 526 conserved metazoan genetic innovations exposes a new role for cofactor E-like in neuronal microtubule homeostasis. PLoS Genet 9: e1003804.

Fujiwara K, Pollard TD. 1976. Fluorescent antibody localization of myosin in the cytoplasm, cleavage furrow, and mitotic spindle of human cells. J Cell Biol 71: 848-875. 
Gai M, Camera P, Dema A, Bianchi F, Berto G, Scarpa E, Germena G, Di Cunto F. 2011. Citron kinase controls abscission through RhoA and anillin. Mol Biol Cell 22: 3768-3778.

Giansanti MG, Farkas RM, Bonaccorsi S, Lindsley DL, Wakimoto BT, Fuller MT, Gatti M. 2004. Genetic dissection of meiotic cytokinesis in Drosophila males. Mol Biol Cell 15: 2509-2522.

Glotzer M. 2009. The 3Ms of central spindle assembly: Microtubules, motors and MAPs. Nat Rev Mol Cell Biol 10: 9-20.

Goss JW, Kim S, Bledsoe H, Pollard TD. 2014. Characterization of the roles of Blt1p in fission yeast cytokinesis. Mol Biol Cell 25: 1946-1957.

Gruneberg U, Neef R, Honda R, Nigg EA, Barr FA. 2004. Relocation of Aurora B from centromeres to the central spindle at the metaphase to anaphase transition requires MKlp2. J Cell Biol 166: 167-172.

Gu Y, Yam C, Oliferenko S. 2015. Rewiring of cellular division site selection in evolution of fission yeasts. Curr Biol 25: 1187-1194.

Guizetti J, Schermelleh L, Mäntler J, Maar S, Poser I, Leonhardt H, Müller-Reichert T, Gerlich DW. 2011. Cortical constriction during abscission involves helices of ESCRT-III-dependent filaments. Science 331: $1616-1620$.

Guzman-Vendrell M, Baldissard S, Almonacid M, Mayeux A, Paoletti A, Moseley JB. 2013. Blt1 and Mid1 provide overlapping membrane anchors to position the division plane in fission yeast. Mol Cell Biol 33: $418-428$.

Haarer BK, Pringle JR. 1987. Immunofluorescence localization of the Saccharomyces cerevisiae CDC12 gene product to the vicinity of the 10-nm filaments in the mother-bud neck. Mol Cell Biol 7: 3678-3687.

Hachet O, Simanis V. 2008. Mid1p/anillin and the septation initiation network orchestrate contractile ring assembly for cytokinesis. Genes Dev 22: 3205-3216.

Henne WM, Buchkovich NJ, Emr SD. 2011. The ESCRT pathway. Dev Cell 21: 77-91.

Hiramoto Y. 1975. Force exerted by the cleavage furrow of sea urchin eggs. Dev Growth Differ 17: 27-38.

Hiramoto Y. 1990. Mechanical properties of the cortex before and during cleavage. Ann NY Acad Sci 582: 22-30.

Hoffman-Berling H. 1954. [Glycerin water extracted telophase cells as a model of cytokinesis]. Biochim Biophys Acta 15: 332-339.

Hu C-K, Ozlü N, Coughlin M, Steen JJ, Mitchison TJ. 2012. Plk1 negatively regulates Prc1 to prevent premature midzone formation before cytokinesis. Mol Biol Cell 23: 2702-2711.

Huang J, Huang Y, Yu H, Subramanian D, Padmanabhan A, Thadani R, Tao Y, Tang X, Wedlich-Soldner R, Balasubramanian MK. 2012. Nonmedially assembled F-actin cables incorporate into the actomyosin ring in fission yeast. J Cell Biol 199: 831-847.

Hutterer A, Glotzer M, Mishima M. 2009. Clustering of centralspindlin is essential for its accumulation to the central spindle and the midbody. Curr Biol 19: 2043-2049.

Jiang W, Jimenez G, Wells NJ, Hope TJ, Wahl GM, Hunter T, Fukunaga R. 1998. PRC1: A human mitotic spindle-associated CDK substrate protein required for cytokinesis. Mol Cell 2: 877-885.

Kamasaki T, Osumi M, Mabuchi I. 2007. Three-dimensional arrangement of F-actin in the contractile ring of fission yeast. J Cell Biol 178: $765-771$.

Kechad A, Jananji S, Ruella Y, Hickson GRX. 2012. Anillin acts as a bifunctional linker coordinating midbody ring biogenesis during cytokinesis. Curr Biol 22: 197-203.

Kim D-W, Sung H, Shin D, Shen H, Ahnn J, Lee S-K, Lee S. 2011. Differential physiological roles of ESCRT complexes in Caenorhabditis elegans. Mol Cells 31: 585-592.

Kosako H, Yoshida T, Matsumura F, Ishizaki T, Narumiya S, Inagaki M. 2000. Rho-kinase/ROCK is involved in cytokinesis through the phosphorylation of myosin light chain and not ezrin/radixin/moesin proteins at the cleavage furrow. Oncogene 19: 6059-6064

Kuo T-C, Chen C-T, Baron D, Onder TT, Loewer S, Almeida S, Weismann CM, Xu P, Houghton J-M, Gao F-B, et al. 2011. Midbody accumulation through evasion of autophagy contributes to cellular reprogramming and tumorigenicity. Nat Cell Biol 13: 1214-1223.
Lafaurie-Janvore J, Maiuri P, Wang I, Pinot M, Manneville J-B, Betz T, Balland M, Piel M. 2013. ESCRT-III assembly and cytokinetic abscission are induced by tension release in the intercellular bridge. Science 339: $1625-1629$.

Laplante C, Berro J, Karatekin E, Hernandez-Leyva A, Lee R, Pollard TD. 2015. Three myosins contribute uniquely to the assembly and constriction of the fission yeast cytokinetic contractile ring. Curr Biol 25: $1955-1965$.

Laporte D, Coffman VC, Lee I-J, Wu J-Q. 2011. Assembly and architecture of precursor nodes during fission yeast cytokinesis. J Cell Biol 192: $1005-1021$

Lee I-J, Wu J-Q. 2012. Characterization of Mid1 domains for targeting and scaffolding in fission yeast cytokinesis. J Cell Sci 125: 2973-2985.

Lee HH, Elia N, Ghirlando R, Lippincott-Schwartz J, Hurley JH. 2008. Midbody targeting of the ESCRT machinery by a noncanonical coiled coil in CEP55. Science 322: 576-580.

Lekomtsev S, Su K-C, Pye VE, Blight K, Sundaramoorthy S, Takaki T, Collinson LM, Cherepanov P, Divecha N, Petronczki M. 2012. Centralspindlin links the mitotic spindle to the plasma membrane during cytokinesis. Nature 492: 276-279.

Li D, Miller M, Chantler PD. 1994. Association of a cellular myosin II with anionic phospholipids and the neuronal plasma membrane. Proc Natl Acad Sci 91: 853-857.

Liljeholm M, Irvine AF, Vikberg A-L, Norberg A, Month S, Sandström H, Wahlin A, Mishima M, Golovleva I. 2013. Congenital dyserythropoietic anemia type III (CDA III) is caused by a mutation in kinesin family member, KIF23. Blood 121: 4791-4799.

Lindås A-C, Karlsson EA, Lindgren MT, Ettema TJG, Bernander R. 2008. A unique cell division machinery in the Archaea. Proc Natl Acad Sci 105: $18942-18946$.

Liu J, Wang H, McCollum D, Balasubramanian MK. 1999. Drc1p/Cps1p, a 1,3- $\beta$-glucan synthase subunit, is essential for division septum assembly in Schizosaccharomyces pombe. Genetics 153: 1193-1203.

Lord M, Laves E, Pollard TD. 2005. Cytokinesis depends on the motor domains of myosin-II in fission yeast but not in budding yeast. Mol Biol Cell 16: 5346-5355.

Loria A, Longhini KM, Glotzer M. 2012. The RhoGAP domain of CYK-4 has an essential role in RhoA activation. Curr Biol 22: 213-219.

Ma X, Jana SS, Conti MA, Kawamoto S, Claycomb WC, Adelstein RS. 2010. Ablation of nonmuscle myosin II-B and II-C reveals a role for nonmuscle myosin II in cardiac myocyte karyokinesis. Mol Biol Cell 21: 3952-3962.

Mabuchi I, Okuno M. 1977. The effect of myosin antibody on the division of starfish blastomeres. J Cell Biol 74: 251-263.

Mabuchi I, Tsukita S, Tsukita S, Sawai T. 1988. Cleavage furrow isolated from newt eggs: Contraction, organization of the actin filaments, and protein components of the furrow. Proc Natl Acad Sci 85: 5966-5970.

Maddox AS, Burridge K. 2003. RhoA is required for cortical retraction and rigidity during mitotic cell rounding. J Cell Biol 160: 255-265.

Matthews HK, Delabre U, Rohn JL, Guck J, Kunda P, Baum B. 2012. Changes in ect2 localization couple actomyosin-dependent cell shape changes to mitotic progression. Dev Cell 23: 371-383.

Maupin P, Pollard TD. 1986. Arrangement of actin filaments and myosinlike filaments in the contractile ring and of actin-like filaments in the mitotic spindle of dividing HeLa cells. J Ultrastruct Mol Struct Res 94: 92-103.

McCullough J, Fisher RD, Whitby FG, Sundquist WI, Hill CP. 2008. ALIX-CHMP4 interactions in the human ESCRT pathway. Proc Natl Acad Sci 105: 7687-7691.

McMurray MA, Stefan CJ, Wemmer M, Odorizzi G, Emr SD, Thorner J. 2011. Genetic interactions with mutations affecting septin assembly reveal ESCRT functions in budding yeast cytokinesis. Biol Chem 392: $699-712$.

Mendes Pinto I, Rubinstein B, Kucharavy A, Unruh JR, Li R. 2012. Actin depolymerization drives actomyosin ring contraction during budding yeast cytokinesis. Dev Cell 22: 1247-1260. 
Mendes Pinto I, Rubinstein B, Li R. 2013. Force to divide: Structural and mechanical requirements for actomyosin ring contraction. Biophys $J$ 105: 547-554.

Mendoza M, Norden C, Durrer K, Rauter H, Uhlmann F, Barral Y. 2009. A mechanism for chromosome segregation sensing by the NoCut checkpoint. Nat Cell Biol 11: 477-483.

Mierzwa B, Gerlich DW. 2014. Cytokinetic abscission: Molecular mechanisms and temporal control. Dev Cell 31: 525-538.

Mishima M, Kaitna S, Glotzer M. 2002. Central spindle assembly and cytokinesis require a kinesin-like protein/RhoGAP complex with microtubule bundling activity. Dev Cell 2: 41-54.

Mishima M, Pavicic V, Gruneberg U, Nigg EA, Glotzer M. 2004. Cell cycle regulation of central spindle assembly. Nature 430: 908-913.

Mishra M, Kashiwazaki J, Takagi T, Srinivasan R, Huang Y, Balasubramanian MK, Mabuchi I. 2013. In vitro contraction of cytokinetic ring depends on myosin II but not on actin dynamics. Nat Cell Biol 15: $853-859$.

Miyazaki M, Chiba M, Eguchi H, Ohki T, Ishiwata S. 2015. Cell-sized spherical confinement induces the spontaneous formation of contractile actomyosin rings in vitro. Nat Cell Biol 17: 480-489.

Morita E, Sandrin V, Chung H-Y, Morham SG, Gygi SP, Rodesch CK, Sundquist WI. 2007. Human ESCRT and ALIX proteins interact with proteins of the midbody and function in cytokinesis. EMBO J 26: $4215-4227$.

Moseley JB, Mayeux A, Paoletti A, Nurse P. 2009. A spatial gradient coordinates cell size and mitotic entry in fission yeast. Nature 459: $857-860$.

Mukhina S, Wang Y-L, Murata-Hori M. 2007. $\alpha$-actinin is required for tightly regulated remodeling of the actin cortical network during cytokinesis. Dev Cell 13: 554-565.

Murthy K, Wadsworth P. 2005. Myosin-II-dependent localization and dynamics of F-actin during cytokinesis. Curr Biol 15: 724-731.

Murthy K, Wadsworth P. 2008. Dual role for microtubules in regulating cortical contractility during cytokinesis. J Cell Sci 121: 2350-2359.

Neujahr R, Heizer C, Gerisch G. 1997. Myosin II-independent processes in mitotic cells of Dictyostelium discoideum: Redistribution of the nuclei, re-arrangement of the actin system and formation of the cleavage furrow. J Cell Sci 110: 123-137.

Nguyen PA, Groen AC, Loose M, Ishihara K, Wühr M, Field CM, Mitchison TJ. 2014. Spatial organization of cytokinesis signaling reconstituted in a cell-free system. Science 346: 244-247.

Oh Y, Schreiter J, Nishihama R, Wloka C, Bi E. 2013. Targeting and functional mechanisms of the cytokinesis-related F-BAR protein Hof1 during the cell cycle. Mol Biol Cell 24: 1305-1320.

Oliferenko S, Chew TG, Balasubramanian MK. 2009. Positioning cytokinesis. Genes Dev 23: 660-674.

Otomo T, Otomo C, Tomchick DR, Machius M, Rosen MK. 2005. Structural basis of Rho GTPase-mediated activation of the formin mDial. Mol Cell 18: 273-281.

Padte NN, Martin SG, Howard M, Chang F. 2006. The cell-end factor pomlp inhibits midlp in specification of the cell division plane in fission yeast. Curr Biol 16: 2480-2487.

Paoletti A, Chang F. 2000. Analysis of mid1p, a protein required for placement of the cell division site, reveals a link between the nucleus and the cell surface in fission yeast. Mol Biol Cell 11: 2757-2773.

Piekny AJ, Glotzer M. 2008. Anillin is a scaffold protein that links RhoA, actin, and myosin during cytokinesis. Curr Biol 18: 30-36.

Poirier CC, Ng WP, Robinson DN, Iglesias PA. 2012. Deconvolution of the cellular force-generating subsystems that govern cytokinesis furrow ingression. PLoS Comp Biol 8: e1002467.

Pu K-M, Akamatsu M, Pollard TD. 2014. The septation initiation network controls the assembly of nodes containing Cdr2p for cytokinesis in fission yeast. J Cell Sci 128: 441-446.

Raich WB, Moran AN, Rothman JH, Hardin J. 1998. Cytokinesis and midzone microtubule organization in Caenorhabditis elegans require the kinesin-like protein ZEN-4. Mol Biol Cell 9: 2037-2049.
Ramanathan SP, Helenius J, Stewart MP, Cattin CJ, Hyman AA, Muller DJ. 2015. Cdk1-dependent mitotic enrichment of cortical myosin II promotes cell rounding against confinement. Nat Cell Biol 17: 148159.

Rappaport R. 1967. Cell division: Direct measurement of maximum tension exerted by furrow of echinoderm eggs. Science 156: 12411243.

Rappaport R. 1985. Repeated furrow formation from a single mitotic apparatus in cylindrical sand dollar eggs. J Exp Zool 234: 167-171.

Rappaport R. 1986. Establishment of the mechanism of cytokinesis in animal cells. Int Rev Cytol 105: 245-281.

Richards TA, Cavalier-Smith T. 2005. Myosin domain evolution and the primary divergence of eukaryotes. Nature 436: 1113-1118.

Roberts-Galbraith RH, Ohi MD, Ballif BA, Chen J-S, McLeod I, McDonald WH, Gygi SP, Yates JR, Gould KL. 2010. Dephosphorylation of F-BAR protein Cdc15 modulates its conformation and stimulates its scaffolding activity at the cell division site. Mol Cell 39: 86-99.

Roubinet C, Decelle B, Chicanne G, Dorn JF, Payrastre B, Payre F, Carreno S. 2011. Molecular networks linked by Moesin drive remodeling of the cell cortex during mitosis. J Cell Biol 195: 99-112.

Ruchaud S, Carmena M, Earnshaw WC. 2007. Chromosomal passengers: Conducting cell division. Nat Rev Mol Cell Biol 8: 798-812.

Samson RY, Obita T, Freund SM, Williams RL, Bell SD. 2008. A role for the ESCRT system in cell division in archaea. Science 322: 1710-1713.

Sanger JM, Sanger JW. 1980. Banding and polarity of actin filaments in interphase and cleaving cells. J Cell Biol 86: 568-575.

Schmidt S, Sohrmann M, Hofmann K, Woollard A, Simanis V. 1997. The Spglp GTPase is an essential, dosage-dependent inducer of septum formation in Schizosaccharomyces pombe. Genes Dev 11: 1519-1534.

Schroeder TE. 1968. Cytokinesis: Filaments in the cleavage furrow. Exp Cell Res 53: 272-276.

Schroeder TE. 1972. The contractile ring. II. Determining its brief existence, volumetric changes, and vital role in cleaving Arbacia eggs. J Cell Biol 53: 419-434.

Sebé-Pedrós A, Grau-Bové X, Richards TA, Ruiz-Trillo I. 2014. Evolution and classification of myosins, a paneukaryotic whole-genome approach. Genome Biol Evol 6: 290-305.

Shim S, Kimpler LA, Hanson PI. 2007. Structure/function analysis of four core ESCRT-III proteins reveals common regulatory role for extreme C-terminal domain. Traffic 8: 1068-1079.

Simanis V. 2015. Pombe's thirteen-Control of fission yeast cell division by the septation initiation network. J Cell Sci 128: 1465-1474.

Sirajuddin M, Farkasovsky M, Hauer F, Kühlmann D, Macara IG, Weyand M, Stark H, Wittinghofer A. 2007. Structural insight into filament formation by mammalian septins. Nature 449: 311-315.

Skau CT, Kovar DR. 2010. Fimbrin and tropomyosin competition regulates endocytosis and cytokinesis kinetics in fission yeast. Curr Biol 20: $1415-1422$.

Spang A, Saw JH, Jørgensen SL, Zaremba-Niedzwiedzka K, Martijn J, Lind AE, van Eijk R, Schleper C, Guy L, Ettema TJG. 2015. Complex archaea that bridge the gap between prokaryotes and eukaryotes. $\mathrm{Na}$ ture 521: 173-179.

Stachowiak MR, Laplante C, Chin HF, Guirao B, Karatekin E, Pollard TD, O’Shaughnessy B. 2014. Mechanism of cytokinetic contractile ring constriction in fission yeast. Dev Cell 29: 547-561.

Steigemann P, Wurzenberger C, Schmitz MHA, Held M, Guizetti J, Maar S, Gerlich DW. 2009. Aurora B-mediated abscission checkpoint protects against tetraploidization. Cell 136: 473-484.

Stewart MP, Helenius J, Toyoda Y, Ramanathan SP, Muller DJ, Hyman AA. 2011. Hydrostatic pressure and the actomyosin cortex drive mitotic cell rounding. Nature 469: 226-230.

Straight AF, Field CM, Mitchison TJ. 2005. Anillin binds nonmuscle myosin II and regulates the contractile ring. Mol Biol Cell 16: 193-201.

Su K-C, Takaki T, Petronczki M. 2011. Targeting of the RhoGEF Ect2 to the equatorial membrane controls cleavage furrow formation during cytokinesis. Dev Cell 21: 1104-1115. 
Su K-C, Bement WM, Petronczki M, Dassow von G. 2014. An astral simulacrum of the central spindle accounts for normal, spindle-less, and anucleate cytokinesis in echinoderm embryos. Mol Biol Cell 25: 4049-4062.

Subramanian R, Wilson-Kubalek EM, Arthur CP, Bick MJ, Campbell EA, Darst SA, Milligan RA, Kapoor TM. 2010. Insights into antiparallel microtubule crosslinking by PRC1, a conserved nonmotor microtubule binding protein. Cell 142: 433-443.

Subramanian R, Ti S-C, Tan L, Darst SA, Kapoor TM. 2013. Marking and measuring single microtubules by PRC1 and Kinesin-4. Cell 154: 377 390.

Sun L, Guan R, Lee I-J, Liu Y, Chen M, Wang J, Wu J-Q, Chen Z. 2015. Mechanistic insights into the anchorage of the contractile ring by anillin and mid1. Dev Cell 33: 413-426.

Takeda K, Kishi H, Ma X, Yu Z-X, Adelstein RS. 2003. Ablation and mutation of nonmuscle myosin heavy chain II-B results in a defect in cardiac myocyte cytokinesis. Circ Res 93: 330-337.

Takeda T, Robinson IM, Savoian MM, Griffiths JR, Whetton AD, McMahon HT, Glover DM. 2013. Drosophila F-BAR protein Syndapin contributes to coupling the plasma membrane and contractile ring in cytokinesis. Open Biol 3: 130081.

Tanaka K, Petersen J, MacIver F, Mulvihill DP, Glover DM, Hagan IM. 2001. The role of Plo1 kinase in mitotic commitment and septation in Schizosaccharomyces pombe. EMBO J 20: 1259-1270.

Tao EY, Calvert M, Balasubramanian MK. 2014. Rewiring Mid1p-independent medial division in fission yeast. Curr Biol 24: 2181-2188.

Teis D, Saksena S, Emr SD. 2008. Ordered assembly of the ESCRT-III complex on endosomes is required to sequester cargo during MVB formation. Dev Cell 15: 578-589.

Tse YC, Piekny A, Glotzer M. 2011. Anillin promotes astral microtubuledirected cortical myosin polarization. Mol Biol Cell 22: 3165-3175.

Tse YC, Werner M, Longhini KM, Labbé J-C, Goldstein B, Glotzer M. 2012. RhoA activation during polarization and cytokinesis of the early Caenorhabditis elegans embryo is differentially dependent on NOP-1 and CYK-4. Mol Biol Cell 23: 4020-4031.

Tsujioka M, Yumura S, Inouye K, Patel H, Ueda M, Yonemura S. 2012. Talin couples the actomyosin cortex to the plasma membrane during rear retraction and cytokinesis. Proc Natl Acad Sci 109: 12992-12997.

Vallen EA, Caviston J, Bi E. 2000. Roles of Hoflp, Bnilp, Bnrlp, and myolp in cytokinesis in Saccharomyces cerevisiae. Mol Biol Cell 11: 593-611.

Vavylonis D, Wu J-Q, Hao S, O'Shaughnessy B, Pollard TD. 2008. Assembly mechanism of the contractile ring for cytokinesis by fission yeast. Science 319: 97-100.

Wagner E, Glotzner M. 2016. Local RhoA activation induces cytokinetic furrows independent of spindle position and cell cycle stage. J Cell Biol 213: 641-649.

Watanabe S, Ando Y, Yasuda S, Hosoya H, Watanabe N, Ishizaki T, Narumiya S. 2008. mDia2 induces the actin scaffold for the contractile ring and stabilizes its position during cytokinesis in NIH 3T3 cells. Mol Biol Cell 19: 2328-2338.

Watanabe S, De Zan T, Ishizaki T, Yasuda S, Kamijo H, Yamada D, Aoki T, Kiyonari H, Kaneko H, Shimizu R, et al. 2013. Loss of a Rho-regulated actin nucleator, $\mathrm{mDia} 2$, impairs cytokinesis during mouse fetal erythropoiesis. Cell Rep 5: 926-932.

White EA, Glotzer M. 2012. Centralspindlin: At the heart of cytokinesis. Cytoskeleton 69: 882-892.
Wloka C, Vallen EA, Thé L, Fang X, Oh Y, Bi E. 2013. Immobile myosin-II plays a scaffolding role during cytokinesis in budding yeast. J Cell Biol 200: $271-286$.

Wolfe BA, Takaki T, Petronczki M, Glotzer M. 2009. Polo-like kinase 1 directs assembly of the HsCyk-4 RhoGAP/Ect2 RhoGEF complex to initiate cleavage furrow formation. PLoS Biol 7: e1000110.

Wollert T, Wunder C, Lippincott-Schwartz J, Hurley JH. 2009. Membrane scission by the ESCRT-III complex. Nature 458: 172-177.

Wu J-Q, Sirotkin V, Kovar DR, Lord M, Beltzner CC, Kuhn JR, Pollard TD. 2006. Assembly of the cytokinetic contractile ring from a broad band of nodes in fission yeast. J Cell Biol 174: 391-402.

Wu J-Q, Pollard TD. 2005. Counting cytokinesis proteins globally and locally in fission yeast. Science 310: 310-314.

Wu J-Q, Kuhn JR, Kovar DR, Pollard TD. 2003. Spatial and temporal pathway for assembly and constriction of the contractile ring in fission yeast cytokinesis. Dev Cell 5: 723-734.

Yang D, Rismanchi N, Renvoisé B, Lippincott-Schwartz J, Blackstone C, Hurley J. 2008. Structural basis for midbody targeting of spastin by the ESCRT-III protein CHMP1B. Nat Struct Mol Biol 15: 1278-1286.

Ye Y, Lee I-J, Runge KW, Wu J-Q. 2012. Roles of putative Rho-GEF Gef2 in division-site positioning and contractile-ring function in fission yeast cytokinesis. Mol Biol Cell 23: 1181-1195.

Yonetani A, Chang F. 2010. Regulation of cytokinesis by the formin cdc12p. Curr Biol 20: 561-566.

Yoshida S, Kono K, Lowery DM, Bartolini S, Yaffe MB, Ohya Y, Pellman D. 2006. Polo-like kinase Cdc5 controls the local activation of Rho1 to promote cytokinesis. Science 313: 108-111.

Young BA, Buser C, Drubin DG. 2010. Isolation and partial purification of the Saccharomyces cerevisiae cytokinetic apparatus. Cytoskeleton 67: $13-22$.

Yüce O, Piekny A, Glotzer M. 2005. An ECT2-centralspindlin complex regulates the localization and function of RhoA. J Cell Biol 170: 571582.

Yumura S. 2001. Myosin II dynamics and cortical flow during contractile ring formation in Dictyostelium cells. J Cell Biol 154: 137-146.

Yumura S, Mori H, Fukui Y. 1984. Localization of actin and myosin for the study of ameboid movement in Dictyostelium using improved immunofluorescence. J Cell Biol 99: 894-899.

Zang JH, Cavet G, Sabry JH, Wagner P, Moores SL, Spudich JA. 1997. On the role of myosin-II in cytokinesis: Division of Dictyostelium cells under adhesive and nonadhesive conditions. Mol Biol Cell 8: $2617-$ 2629.

Zhang D, Glotzer M. 2015. The RhoGAP activity of CYK-4/MgcRacGAP functions non-canonically by promoting RhoA activation during cytokinesis. Elife 4: e08898.

Zhao W-M, Seki A, Fang G. 2006. Cep55, a microtubule-bundling protein, associates with centralspindlin to control the midbody integrity and cell abscission during cytokinesis. Mol Biol Cell 17: 38813896.

Zhou Z, Munteanu EL, He J, Ursell T, Bathe M, Huang KC, Chang F. 2015. The contractile ring coordinates curvature-dependent septum assembly during fission yeast cytokinesis. Mol Biol Cell 26: 78-90.

Zhu C, Zhu C, Lau E, Lau E, Schwarzenbacher R, Schwarzenbacher R, Bossy-Wetzel E, Bossy-Wetzel E, Jiang W, Jiang W. 2006. Spatiotemporal control of spindle midzone formation by PRC1 in human cells. Proc Natl Acad Sci 103: 6196-6201. 


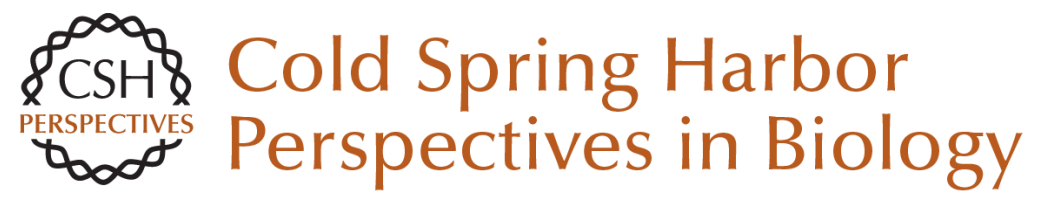

\title{
Cytokinesis in Metazoa and Fungi
}

\author{
Michael Glotzer
}

Cold Spring Harb Perspect Biol 2017; doi: 10.1101/cshperspect.a022343 originally published online December 22, 2016

\section{Subject Collection The Cytoskeleton}

\section{Microtubules and Microtubule-Associated \\ Proteins \\ Holly V. Goodson and Erin M. Jonasson \\ Motor Proteins \\ H. Lee Sweeney and Erika L.F. Holzbaur \\ Myosin-Driven Intracellular Transport \\ Margaret $A$. Titus \\ The Actin Cytoskeleton and Actin-Based Motility Tatyana Svitkina}

\section{Mechanical Properties of the Cytoskeleton and Cells}

Adrian F. Pegoraro, Paul Janmey and David A. Weitz

Intermediate Filaments and the Regulation of Cell Motility during Regeneration and Wound Healing Fang Cheng and John E. Eriksson

Intermediate Filaments and the Plasma Membrane Jonathan C.R. Jones, Chen Yuan Kam, Robert M. Harmon, et al.

\author{
Overview of the Cytoskeleton from an \\ Evolutionary Perspective \\ Thomas D. Pollard and Robert D. Goldman \\ Types I and II Keratin Intermediate Filaments \\ Justin T. Jacob, Pierre A. Coulombe, Raymond \\ Kwan, et al.

\section{Muscle Contraction} \\ H. Lee Sweeney and David W. Hammers \\ Type III Intermediate Filaments Desmin, Glial \\ Fibrillary Acidic Protein (GFAP), Vimentin, and \\ Peripherin \\ Elly M. Hol and Yassemi Capetanaki \\ Cytokinesis in Metazoa and Fungi \\ Michael Glotzer
}

\section{Ciliary Motility: Regulation of Axonemal Dynein} Motors

Rasagnya Viswanadha, Winfield S. Sale and Mary E. Porter

Actin-Based Adhesion Modules Mediate Cell Interactions with the Extracellular Matrix and Neighboring Cells Alexia I. Bachir, Alan Rick Horwitz, W. James Nelson, et al.

For additional articles in this collection, see http://cshperspectives.cshlp.org/cgi/collection/

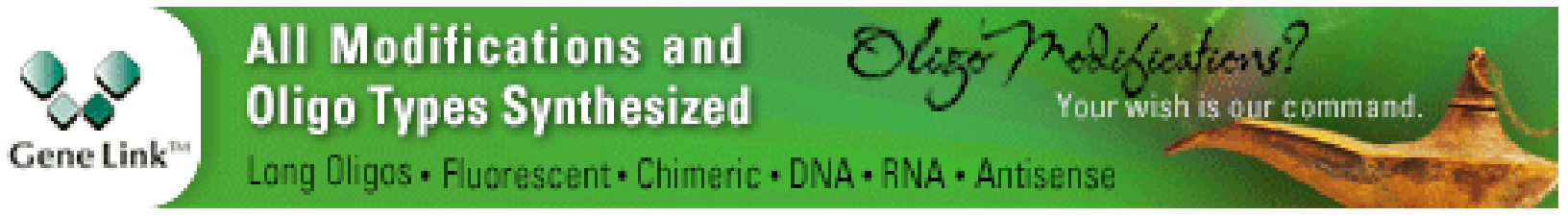

Copyright @ 2017 Cold Spring Harbor Laboratory Press; all rights reserved 
Intracellular Motility of Intermediate Filaments Rudolf E. Leube, Marcin Moch and Reinhard Windoffer
Microtubule-Based Transport and the Distribution, Tethering, and Organization of Organelles Kari Barlan and Vladimir I. Gelfand

For additional articles in this collection, see http://cshperspectives.cshlp.org/cgi/collection/

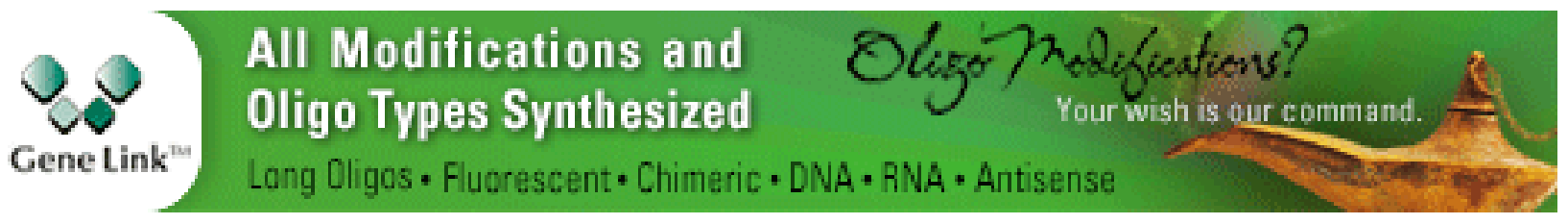

Copyright @ 2017 Cold Spring Harbor Laboratory Press; all rights reserved 